\title{
Synthesis of $\mathrm{rGO}-\mathrm{Fe}_{3} \mathrm{O}_{4}-\mathrm{SnO}_{2}$ - $\mathrm{C}$ Quaternary Hybrid Mesoporous
}

\section{Nanosheets as a High-performance Anode Material for Lithium Ion}

\section{Batteries}

Guoen Luo ${ }^{a}$, Yuheng Lu ${ }^{a}$, Songshan Zeng ${ }^{b}$, Saibin Zhong ${ }^{a}$, Xiaoyuan Yu ${ }^{a} *$, Yueping Fang ${ }^{a}$, Luyi $^{2}$

$$
\mathrm{Sun}^{b} *
$$

${ }^{\mathrm{a}}$ Institute of Biomaterial, College of Materials and Energy, South China Agricultural University, Guangzhou 510642, China

${ }^{\mathrm{b}}$ Institute of Materials Science, Department of Chemical \& Biomolecular Engineering and Polymer Program, University of Connecticut, Storrs, Connecticut 06269, United States

\begin{abstract}
A quaternary hierarchical nanocomposite, $\mathrm{rGO}-\mathrm{Fe}_{3} \mathrm{O}_{4}-\mathrm{SnO}_{2}-\mathrm{C}$, is rationally designed and synthesized via layer-by-layer constructions of reduced graphene oxide (rGO) flexible films, $\mathrm{Fe}_{3} \mathrm{O}_{4}$ nanoparticles, $\mathrm{SnO}_{2}$ nanoparticles and an omnidirectional amorphous carbon layer. SEM and TEM observations show that the $\mathrm{Fe}_{3} \mathrm{O}_{4}$ and $\mathrm{SnO}_{2}$ nanoparticles are uniformly dispersed on the rGO nanosheets and fully encapsulated by the outmost carbon layers, forming a sandwich-like buffering structure for excellent dimensional integrity. Furthermore, nanopores with an average size of $5.8 \mathrm{~nm}$ are fabricated within the quaternary hybrid nanosheets via a layer-by-layer packing of $\mathrm{Fe}_{3} \mathrm{O}_{4}$ and $\mathrm{SnO}_{2}$ nanoparticles, which possess the different shapes and sizes. Galvanostatic charge/discharge measurements demonstrate that $\mathrm{rGO}-\mathrm{Fe}_{3} \mathrm{O}_{4}-\mathrm{SnO}_{2}-\mathrm{C}$ exhibits a reversible capacity of $868.6 \mathrm{mAh} \mathrm{g}^{-1}$ after 100 cycles at a current density of $200 \mathrm{~mA} \mathrm{~g}^{-1}$. Even at a current density of $2.0 \mathrm{~A} \mathrm{~g}^{-1}$, it can be stably operated during the discharge/charge processes and deliver a reversible capacity of $414.7 \mathrm{mAh} \mathrm{g}^{-1}$. The excellent electrochemical properties of rGO-Fe $\mathrm{O}_{4}-\mathrm{SnO}_{2}-\mathrm{C}$ can be attributed to the microstructural stability of the hybrid and the synergistic effects of the components inside the nanosheets.
\end{abstract}

Keywords: Ferroferric oxide; Tin oxide; Graphene; Nanosheets; Lithium ion batteries 
*Corresponding authors

(X. Y. Yu) Tel: (86)134-1629-1988; Fax: 86-20-8528-5026; E-mail: yuxiaoyuan@scau.edu.cn

(L. Y. Sun) Tel: 860-486-6895; Fax: 860-486-4745; E-mail:luyi.sun@uconn.edu

\section{Introduction}

With the rapid development of portable electronics and hybrid electric vehicles, lithium-ion batteries (LIBs) have suffered from the limited gravimetric capacities of the electrode materials [1-3]. As for anode materials, a standard commercialized carbon-based material can deliver a gravimetric specific capacity of only about $372 \mathrm{mAh} \mathrm{g}^{-1}$, which can not meet the urgent demand for high performance energy storage [4,5]. Transition metal oxides (TMOs), such as iron oxides $[6,7]$, tin oxides [8,9], manganese oxides [10,11], and cobalt oxides [12,13], have attracted much attention as promising anode materials for the next generation of LIBs because of their advantages of high energy and power density $[14,15]$. For instance, $\mathrm{Fe}_{3} \mathrm{O}_{4}$ and $\mathrm{SnO}_{2}$ exhibit the attractive theoretical capacities of $924 \mathrm{mAh} \mathrm{g}^{-1}$ and $780 \mathrm{mAh} \mathrm{g}^{-1}$, respectively, based on the following lithium storage mechanisms (eq 1, 2, and 3) [16, 17]:

$$
\begin{aligned}
& \mathrm{Fe}_{3} \mathrm{O}_{4}+8 \mathrm{Li}^{+}+8 \mathrm{e}^{-} \leftrightarrow 3 \mathrm{Fe}+4 \mathrm{Li}_{2} \mathrm{O} \\
& \mathrm{SnO}_{2}+4 \mathrm{Li}^{+}+4 \mathrm{e}^{-} \rightarrow \mathrm{Sn}+2 \mathrm{Li}_{2} \mathrm{O} \\
& \mathrm{Sn}+x \mathrm{Li}^{+}+x \mathrm{e}^{-} \leftrightarrow \mathrm{Li}_{x} \mathrm{Sn}(0 \leq x \leq 4.4)
\end{aligned}
$$

However, most of the transition metal oxide electrode materials suffer from the Li-alloying agglomeration [18] and the growth of passivation layers [19] along with tremendous volume changes and stresses, and subsequent falling of the active materials from the electrode, resulting in the significant capacity fading during the lithiation/delithiation process [20,21]. So far, three main strategies have been widely used to improve the electrochemical performance of the transition metal oxide electrodes [22-24]: (I) Construction of mesoporous nanostructures, such as 
nanoparticles (NPs) [25], nanospheres [26], nanotubes [27] and nanosheets [28], in order to keep the absolute small volume changes and stabilize the dimensional integrity and the microstructure of the overall material during cycling. For example, Liu et al. [29] synthesized the amorphous $\mathrm{SnO}_{2}$ nano-membranes as anodes for LIBs, which demonstrated a long cycling life of 1000 cycles at $1600 \mathrm{~mA} \mathrm{~g}^{-1}$ with a high reversible capacity of $854 \mathrm{mAh} \mathrm{g}^{-1}$. (II) Fabrication of active/inactive composites, which involves intimately mixing two materials, one reacts with lithium whereas the other acts as an inactive confining buffer, such as $\mathrm{Ag} / \mathrm{Fe}_{3} \mathrm{O}_{4}$ [30] and $\mathrm{MnO}_{2} @ \mathrm{Fe}_{2} \mathrm{O}_{3}$ [31]. It is reported that iron oxides and tin oxides can be combined as a relative active/inactive composite [32]. Due to the different lithium uptake/release potentials of the metal oxides, tin oxide NPs is effective to prevent the aggregation of iron oxide NPs during electrochemical cycling. (III) Buffering of the volume expansion/shrinkage from flexible materials, such as carbon [20,25-27] and polymer [33]. Carbon-based materials are the most widely used buffers for MO anodes thanks to their advantages of high conductivity, mechanical flexibility, chemical stability, and large surface area, which are effective to enhance the structural stability and electric conductivity of the electrode. It is worthy to mention that a new type of $\mathrm{C}_{1}-\mathrm{MO}-\mathrm{C}_{2}\left(\mathrm{C}_{1}\right.$ : graphene nanosheets $(\mathrm{GNs})$ [34,35], carbon nanofibers (CNFs) [36], carbon nanotubes (CNTs) [37]; $\mathrm{C}_{2}$ : amorphous nanocarbon) carbon-based sandwiched buffering structure has been developed in recent years. In this type of hybrid material, $\mathrm{C}_{1}$ is defined as an efficient support or substrate carbon material to disperse $\mathrm{MO}$ particles well, $\mathrm{C}_{2}$ is amorphous nanocarbon with good elasticity covering over the MO particles to effectively accommodate the strain of volume change and preventing MO particles from falling off from the substrate material. For instance, Huang et al. [38] reported the synthesis and electrochemical properties of $\mathrm{rGO}-\mathrm{SnO}_{2}-\mathrm{C}$ and $\mathrm{rGO}-\mathrm{Fe}_{2} \mathrm{O}_{3}-\mathrm{C}$. Except for the initial cycles, the rGO-MO-C type hybrids exhibited excellent cycling performances at various current densities. However, the reversible capacities of the anodes still need to be improved. Besides, it is very challenging to design approaches to simultaneously combine the support, MO NPs, and the carbon coating in one material system to synthesize $\mathrm{C}_{1}-\mathrm{MO}-\mathrm{C}_{2}$ type hybrid materials.

In this work, based on the three aforementioned strategies, we designed a simple approach to 
fabricate $\mathrm{C}_{1}-\mathrm{MO}_{1}-\mathrm{MO}_{2}-\mathrm{C}_{2}$ type quaternary hybrid materials for high performance energy storage. As a result, $\mathrm{rGO}-\mathrm{Fe}_{3} \mathrm{O}_{4}-\mathrm{SnO}_{2}-\mathrm{C}$ hybrid nanosheets with numerous nano pores were synthesized using reduced graphene oxide as a substrate for layer-by-layer precipitation of $\mathrm{Fe}_{3} \mathrm{O}_{4}$ and $\mathrm{SnO}_{2}$ nanoparticles, and finally encapsulated by omnidirectional amorphous nanocarbon. Compared to the typical $\mathrm{C}_{1}-\mathrm{MO}-\mathrm{C}_{2}$ material, in addition to the advanced sandwiched structure carbon buffering, $\mathrm{Fe}_{3} \mathrm{O}_{4}$ and $\mathrm{SnO}_{2}$ was combined as a relative active/inactive electrochemical system in order to effectively prevent the aggregation and enhance the electronic conductivity of the anode material during the cycles. Besides, the nano pores inside the nanosheets are beneficial to accommodate the substantial volume changes of MO NPs and enhance the reversible capacity of the material. It can be speculated that this type of $\mathrm{C}_{1}-\mathrm{MO}_{1}-\mathrm{MO}_{2}-\mathrm{C}_{2}$ hybrid material would overcome the drawbacks of MOs and thus obtain improved electrochemical performance as a promising anode material for high performance lithium ion batteries.

\section{Experiment}

\subsection{Materials Preparation}

The $\mathrm{rGO}-\mathrm{Fe}_{3} \mathrm{O}_{4}-\mathrm{SnO}_{2}-\mathrm{C}$ mesoporous hybrid nanosheets were synthesized via layer-by-layer in situ homogeneous precipitations of $\mathrm{FeOOH}$ and $\mathrm{SnO}_{2}$ nanoparticles onto graphene oxide (GO) nanosheets, followed by a hydrothermal treatment of glucose for the construction of omnidirectional encapsulated amorphous carbon. GO was prepared from natural graphite flakes by a modified Hummers method [39, 40]. For the preparation of GO-FeOOH, $0.68 \mathrm{~g} \mathrm{FeCl}_{3} \cdot 6 \mathrm{H}_{2} \mathrm{O}$ was added to $250 \mathrm{~mL}$ of $\mathrm{GO}$ aqueous solution (containing $0.10 \mathrm{~g} \mathrm{GO}$, exfoliated by ultrasonication for $1 \mathrm{~h}$ ) under constant mechanical stirring. After stirring for $0.5 \mathrm{~h}$, the mixture was heated to $80{ }^{\circ} \mathrm{C}$ and kept for $12 \mathrm{~h}$. After the $\mathrm{GO}-\mathrm{FeOOH}$ mixture was cooled down, $0.53 \mathrm{~g} \mathrm{Na}_{2} \mathrm{SnO}_{3}$ was added as a source of $\mathrm{SnO}_{2}$ and sonicated for $0.5 \mathrm{~h}$, then reacted at room temperature for $24 \mathrm{~h}$ under mechanical stirring. The resulting suspension $\mathrm{GO}-\mathrm{FeOOH}-\mathrm{SnO}_{2}$ was collected by centrifugation, washed with deionized water, and then vacuum-dried at $50^{\circ} \mathrm{C}$ for $24 \mathrm{~h}$. For the carbon precursor coating process, $0.35 \mathrm{~g}$ glucose and $1.05 \mathrm{~g}$ urea was dissolved in $22 \mathrm{~mL}$ deionized water and $13 \mathrm{~mL}$ 
ethanol until a clear solution was observed. Subsequently, $0.1 \mathrm{~g} \mathrm{GO}-\mathrm{FeOOH}-\mathrm{SnO}_{2}$ was added and dispersed by ultrasonication before transferring to a $50 \mathrm{~mL}$ Teflon autoclave, which was subsequently heated at $180{ }^{\circ} \mathrm{C}$ for $12 \mathrm{~h}$. After cooling to room temperature, the suspension was harvested by centrifugation and then dried in a vacuum oven at $50^{\circ} \mathrm{C}$ for $24 \mathrm{~h}$, followed by heating in a tube furnace under $\mathrm{N}_{2}$ at $450{ }^{\circ} \mathrm{C}$ for $3 \mathrm{~h}$.

For comparison, $\mathrm{rGO}-\mathrm{Fe}_{3} \mathrm{O}_{4}-\mathrm{C}$ was synthesized via the same carbon coating process with $\mathrm{GO}-\mathrm{FeOOH}$ instead of GO-FeOOH$-\mathrm{SnO}_{2}$ followed by heating under $\mathrm{N}_{2}$ at $450{ }^{\circ} \mathrm{C}$ for $3 \mathrm{~h}$. The rGO-Fe $\mathrm{O}_{4}-\mathrm{SnO}_{2}$ was obtained through an in situ transformation of $\mathrm{GO}-\mathrm{FeOOH}-\mathrm{SnO}_{2}$ by the same heat treatment.

\subsection{Characterization}

The structure and morphology of the as-prepared samples were characterized by X-ray diffraction (XRD, D/Max-Ш X-ray diffractometer with $\mathrm{Cu} \mathrm{K} \alpha$ radiation), laser Raman spectroscopy (Renishaw in Via), scanning electron microscopy (SEM; JEOL JSM-6380LA), and transmission electron microscopy (TEM, Hitachi, H-800). Nitrogen adsorptiondesorption isotherms were measured on a Gemini-2390 analyzer (Micromeritics Co., USA) at $77 \mathrm{~K}$. The Brunauer-Emmett-Teller (BET) method was utilized to calculate the specific surface area, while the Barrett-Joyner-Halenda $(\mathrm{BJH})$ method was used to derive pore-size distributions from the desorption branches of the isotherms. The total pore volumes, $\mathrm{Vp}$, were estimated from the amount adsorbed at a relative pressure of $\mathrm{P} / \mathrm{P}_{0}=0.95$. In addition, thermogravimetric analysis (TGA) was carried out on a Netzsch TG 209 apparatus under an air flow at a rate of $30 \mathrm{~mL} \mathrm{~min}^{-1}$ with a heating rate of $15^{\circ} \mathrm{C} \mathrm{min}^{-1}$.

\subsection{Electrochemical measurements}

The working electrode was composed of the testing material $\left(\mathrm{rGO}-\mathrm{Fe}_{3} \mathrm{O}_{4}-\mathrm{C}\right.$, rGO-Fe $\mathrm{O}_{4}-\mathrm{SnO}_{2}$ or $\left.\mathrm{rGO}-\mathrm{Fe}_{3} \mathrm{O}_{4}-\mathrm{SnO}_{2}-\mathrm{C}\right)$, conductive carbon black and polyvinylidene fluoride (PVDF) in a mass ratio of 7:2:1. The CR2025 coin cells were assembled in a glove box filled with ultrapure argon, using lithium metal as the counter electrode, $1.0 \mathrm{~mol} / \mathrm{L} \mathrm{LiPF}$ in ethylene carbonate/dimethyl carbonate $(\mathrm{v} / \mathrm{v}=1: 1)$ as electrolyte, and microporous polypropylene film 
(Celgard 2400) as a separator. The cells were kept at room temperature for 24 hours before electrochemical testing. Galvanostatic charge/discharge tests were performed on a Neware battery test system at room temperature and various rates between cutoff potentials of 0.01 and 3.0 V (vs. $\mathrm{Li} / \mathrm{Li}^{+}$). Electrochemical impedance spectroscopy measurements were performed in the frequency range from $10 \mathrm{mHz}$ to $1 \mathrm{MHz}$ by applying an alternating-current (ac) signal of 5 $\mathrm{mV}$.

\section{Results and discussion}

The synthesis process of $\mathrm{rGO}-\mathrm{Fe}_{3} \mathrm{O}_{4}-\mathrm{SnO}_{2}-\mathrm{C}$ mesoporous hybrid nanosheets is illustrated in Scheme 1. First, $\mathrm{Fe}^{3+}$ cations from $\mathrm{FeCl}_{3}$ were favorably binded onto $\mathrm{GO}$ sheets via electrostatic interactions and in situ hydrolyzed to immobilize FeOOH NPs onto the GO sheets. Second, as the remnant $\mathrm{Fe}^{3+}$ cations were adsorbed by $\mathrm{FeOOH} \mathrm{NPs,} \mathrm{SnO}_{3}{ }^{2-}$ anions were concentrated on the surface of the GO-FeOOH nanosheets and hydrolyzed at room temperature to provide ultrafine $\mathrm{SnO}_{2} \mathrm{NPs}$ for a second homogeneous precipitation on the GO-FeOOH nanosheets. Finally, amorphous nanocarbon was formed among the metal oxide NPs on GO-FeOOH-SnO 2 by hydrothermal carbonization of glucose. During the heating process, the GO was in situ transformed into $\mathrm{rGO}$ and the $\mathrm{FeOOH}$ was transformed into $\mathrm{Fe}_{3} \mathrm{O}_{4}$ simultaneously to obtain rGO-Fe $\mathrm{O}_{4}-\mathrm{SnO}_{2}-\mathrm{C}$ mesoporous hybrid nanosheets.

Fig. 1 presents the SEM images of $\mathrm{rGO}-\mathrm{Fe}_{3} \mathrm{O}_{4}-\mathrm{C}, \mathrm{rGO}-\mathrm{Fe}_{3} \mathrm{O}_{4}-\mathrm{SnO}_{2}$ and $\mathrm{rGO}-\mathrm{Fe}_{3} \mathrm{O}_{4}-\mathrm{SnO}_{2}-\mathrm{C}$ composites. It is showed that all the samples exhibit a sheet-like structure because of using rGO as a substrate. However, the surface morphology of the samples is quite different. It is obvious that the metal oxide NPs of $\mathrm{rGO}-\mathrm{Fe}_{3} \mathrm{O}_{4}-\mathrm{SnO}_{2}-\mathrm{C}$ and $\mathrm{rGO}-\mathrm{Fe}_{3} \mathrm{O}_{4}-\mathrm{C}$ have been successfully anchored onto both sides of the rGO nanosheets, while those of $\mathrm{rGO}-\mathrm{Fe}_{3} \mathrm{O}_{4}-\mathrm{SnO}_{2}$ have seriously self-aggregated from nanoscale into microscale probably due to the high temperature heat treatment. The much smoother surfaces of the two samples, especially $\mathrm{rGO}-\mathrm{Fe}_{3} \mathrm{O}_{4}-\mathrm{SnO}_{2}-\mathrm{C}$ hybrid nanosheets, indicates that the metal oxide NPs have been fully encapsulated by the amorphous nanocarbon layer to form a sandwiched hierarchical structure with the substrate of 
rGO. On the other hand, by intimately mixing the $\mathrm{Fe}_{3} \mathrm{O}_{4}$ and $\mathrm{SnO}_{2} \mathrm{NPs}$, the $\mathrm{rGO}-\mathrm{Fe}_{3} \mathrm{O}_{4}-\mathrm{SnO}_{2}-\mathrm{C}$ nanosheets show a more packed arrangement and an excellent integrity to uniformly distribute metal oxide NPs on the surface of the rGO. Meanwhile, the average thickness of rGO-Fe ${ }_{3} \mathrm{O}_{4}-\mathrm{SnO}_{2}-\mathrm{C}$ nanosheets was increased slightly, which helps to keep them from severe stacking like $\mathrm{rGO}_{-} \mathrm{Fe}_{3} \mathrm{O}_{4}-\mathrm{SnO}_{2}$. From the EDS analysis (Fig. S1), the mole ratio of $\mathrm{Fe}$ and $\mathrm{Sn}$ atoms in the $\mathrm{rGO}-\mathrm{Fe}_{3} \mathrm{O}_{4}-\mathrm{SnO}_{2}-\mathrm{C}$ composite is ca. 2.6.

The TEM images of $\mathrm{rGO}-\mathrm{Fe}_{3} \mathrm{O}_{4}-\mathrm{C}, \mathrm{rGO}-\mathrm{Fe}_{3} \mathrm{O}_{4}-\mathrm{SnO}_{2}$ and $\mathrm{rGO}-\mathrm{Fe}_{3} \mathrm{O}_{4}-\mathrm{SnO}_{2}-\mathrm{C}$ hybrids with different magnifications are shown in Fig. 2. After a strong ultrasonic treatment during preparation of the TEM samples, we can observe that the metal oxide NPs of $\mathrm{rGO}-\mathrm{Fe}_{3} \mathrm{O}_{4}-\mathrm{C}$ and rGO-Fe $\mathrm{O}_{4}-\mathrm{SnO}_{2}-\mathrm{C}$ were firmly decorated on the surface of the rGO nanosheets, while those of rGO-Fe $\mathrm{O}_{4}-\mathrm{SnO}_{2}$ fell off, indicating that the coated carbon is effective to root the metal oxide NPs onto rGO nanosheets. At a higher magnification, it is found that the particles of the rGO-Fe $\mathrm{O}_{4}-\mathrm{SnO}_{2}-\mathrm{C}$ hybrid nanosheets, in comparison to $\mathrm{rGO}-\mathrm{Fe}_{3} \mathrm{O}_{4}-\mathrm{C}$, are better-defined and the size distribution is narrowed into the range of 3-15 nm. Besides, the shapes of $\mathrm{SnO}_{2} \mathrm{NPs}$ and $\mathrm{Fe}_{3} \mathrm{O}_{4}$ NPs in the hybrid nanosheets are quite different and the size of $\mathrm{SnO}_{2}$ NPs is much smaller than that of $\mathrm{Fe}_{3} \mathrm{O}_{4}$ NPs (3-5 nm for $\mathrm{SnO}_{2}$ NPs and 10-15 nm for $\mathrm{Fe}_{3} \mathrm{O}_{4} \mathrm{NPs}$ ). The selected area electron diffraction (SEAD) image of $\mathrm{rGO}-\mathrm{Fe}_{3} \mathrm{O}_{4}-\mathrm{SnO}_{2}-\mathrm{C}$ shows the multiple directional growth and low degree of crystallinity of the $\mathrm{Fe}_{3} \mathrm{O}_{4}$ and $\mathrm{SnO}_{2} \mathrm{NPs}$ in the hybrid. It is rational to infer that besides the ultrathin carbon layer, the intimate deposition of $\mathrm{SnO}_{2}$ NPs was also beneficial to hinder the agglomeration of $\mathrm{Fe}_{3} \mathrm{O}_{4}$ NPs during the high temperature heat treatment, as the $\mathrm{Fe}_{3} \mathrm{O}_{4}$ NPs came from the decomposition and transformation of $\mathrm{FeOOH}$ with a tendency to get together. The efficient assembly of $\mathrm{rGO}$ flexible films, $\mathrm{Fe}_{3} \mathrm{O}_{4}$ and $\mathrm{SnO}_{2} \mathrm{NPs}$, and amorphous carbon of the rGO- $\mathrm{Fe}_{3} \mathrm{O}_{4}-\mathrm{SnO}_{2}-\mathrm{C}$ hybrid nanosheets was achieved to enhance their interface contact and suppress the dissolution and agglomeration of particles, thereby promoting the structural stability and promising for high electrochemical activity.

To gain an insight into the internal structure of the composites, XRD experiments were carried out, as shown in Fig. 3a. The XRD patterns for $\mathrm{rGO}-\mathrm{Fe}_{3} \mathrm{O}_{4}-\mathrm{SnO}_{2}-\mathrm{C}$ and $\mathrm{rGO}-\mathrm{Fe}_{3} \mathrm{O}_{4}-\mathrm{SnO}_{2}$ 
are quite similar, and all intensive peaks match well with the standard patterns of $\mathrm{SnO}_{2}(\mathrm{JCPDS}$ no. 41-1445) and $\mathrm{Fe}_{3} \mathrm{O}_{4}$ (JCPDS no. 65-3107), indicating that the crystal structure of $\mathrm{SnO}_{2}$ and $\mathrm{Fe}_{3} \mathrm{O}_{4}$ remains intact after encapsulated by the carbon layer. No apparent diffraction peak at $26^{\circ}$ corresponding to graphene was observed in the patterns of the samples. The characteristic peaks of $\mathrm{Fe}_{3} \mathrm{O}_{4}$ and $\mathrm{SnO}_{2}$ for $\mathrm{rGO}-\mathrm{Fe}_{3} \mathrm{O}_{4}-\mathrm{SnO}_{2}-\mathrm{C}$ are considerably broadened, and the peak intensity is much weaker in comparison to $\mathrm{rGO}-\mathrm{Fe}_{3} \mathrm{O}_{4}-\mathrm{SnO}_{2}$, which therefore indicates that the MO NPs have a lower crystallinity (higher content of amorphous phase) and smaller particle size. In general, MOs with a low crystallinity is less likely to suffer structural collapse during charge/discharge processes as compared with the amorphous counterparts [41]. Because a lower degree of crystallinity is associated with a homogenous volume expansion and contraction, thus eliminating the existence of two phase regions and improving the cycling stability [42].

To quantify the contents of metal oxide NPs, carbon and rGO in the composites, thermogravimetric analysis (TGA) was carried out in air with a temperature range from room temperature to $800^{\circ} \mathrm{C}$, as shown in Fig. 3 b. The miniscule weight loss that appeared below $150{ }^{\circ} \mathrm{C}$ was attributed to the evaporation of adsorbed water and the major weight loss from 300 to $600{ }^{\circ} \mathrm{C}$ indicated the combustion of rGO and carbon. It should be noted that the slight weight increase between 150 to $300{ }^{\circ} \mathrm{C}$ for $\mathrm{rGO}-\mathrm{Fe}_{3} \mathrm{O}_{4}-\mathrm{C}$ was due to the oxidation of $\mathrm{Fe}_{3} \mathrm{O}_{4}$. It is shown that the weight ratio of $\mathrm{rGO}$ is calculated as $6.7 \%$ for $\mathrm{rGO}-\mathrm{Fe}_{3} \mathrm{O}_{4}-\mathrm{SnO}_{2}$. With further carbon coating, the total weight ratio of $\mathrm{rGO}$ and carbon for $\mathrm{rGO}-\mathrm{Fe}_{3} \mathrm{O}_{4}-\mathrm{SnO}_{2}-\mathrm{C}$ increased to ca. $27.7 \%$, indicating that the total weight ratio of $\mathrm{Fe}_{3} \mathrm{O}_{4}$ and $\mathrm{SnO}_{2}$ NPs was ca. $72.3 \%$. Without the deposition of $\mathrm{SnO}_{2}$ NPs, the weight ratio of $\mathrm{rGO}$ and carbon for $\mathrm{rGO}-\mathrm{Fe}_{3} \mathrm{O}_{4}-\mathrm{C}$ was a little higher and reached ca. $33.3 \%$, implying a thicker carbon layer for the $\mathrm{Fe}_{3} \mathrm{O}_{4}$ NPs of the sample.

Raman spectrum of $\mathrm{rGO}-\mathrm{Fe}_{3} \mathrm{O}_{4}-\mathrm{SnO}_{2}-\mathrm{C}$ is presented in Figure 3c. It shows a fairly strong D band in the vicinity of $1359 \mathrm{~cm}^{-1}$ corresponding to the $\mathrm{A}_{1 \mathrm{~g}}$ symmetry mode of carbon atoms and a sharp $\mathrm{G}$ band in the vicinity of $1596 \mathrm{~cm}^{-1}$ corresponding to the $\mathrm{E}_{2 \mathrm{~g}}$ mode of the $\mathrm{sp}^{2}$ carbon atoms [43]. For further analysis, the Raman spectrum was separated into four bands by a multiple peak fit with a Voigt profile function. The fitting results are shown in Figure $3 \mathrm{c}$ and table 1.It is 
reported that the $1598 \mathrm{~cm}^{-1}$ band ( $\mathrm{G}$ band) is characteristic of the ideal graphitic lattice vibration mode and corresponds to the in-plane vibration of graphite; The $1360 \mathrm{~cm}^{-1}$ band (D band) corresponds to in-plane defects of $\mathrm{sp}^{2}$ carbon; The $1523 \mathrm{~cm}^{-1}$ band (D3 band) is attributed to the defects outside the planes of aromatic layers, such as tetrahedral carbon; The $1230 \mathrm{~cm}^{-1}$ band (D4 band) is attributed to the stretching vibration of aliphatic carbon $[44,45]$. The high value of $I_{\mathrm{D}} / I_{\mathrm{G}}$ indicates the disordered structure of amorphous nanocarbon and the defects inside rGO films, which can provide more active sides for lithium intercalation. On the other hand, the relative low value of $\left(A_{\mathrm{D} 3}+A_{\mathrm{D} 4}\right) /\left(A_{\mathrm{D}}+A_{\mathrm{G}}\right)$ indicates a high content of $\mathrm{sp}^{2}$ carbon, which can improve the electronic conductivity of the anode material and thus provide better electronic contact for high power performance.

The surface area of the $\mathrm{rGO}-\mathrm{Fe}_{3} \mathrm{O}_{4}-\mathrm{C}$ and $\mathrm{rGO}-\mathrm{Fe}_{3} \mathrm{O}_{4}-\mathrm{SnO}_{2}-\mathrm{C}$ composites was characterized by nitrogen adsorption and desorption isotherms, as displayed in Fig. 4. the specific surface area of $\mathrm{rGO}-\mathrm{Fe}_{3} \mathrm{O}_{4}-\mathrm{SnO}_{2}-\mathrm{C}$ is $96.4 \mathrm{~m}^{2} \mathrm{~g}^{-1}$, which was much higher than that of $\mathrm{rGO}-\mathrm{Fe}_{3} \mathrm{O}_{4}-\mathrm{C}\left(38.9 \mathrm{~m}^{2}\right.$ $\mathrm{g}^{-1}$ ). Moreover, the pore size distribution calculated by the Blaryater-Halenda (BJH) method ranged from 2.0 to $100 \mathrm{~nm}$ (insets in Fig. 4). For the $\mathrm{rGO}-\mathrm{Fe}_{3} \mathrm{O}_{4}-\mathrm{C}$ composite, the average pore diameter is about $27.0 \mathrm{~nm}$ distributed from $2.5 \mathrm{~nm}$ to $70 \mathrm{~nm}$. However, the average pore diameter of $\mathrm{rGO}-\mathrm{Fe}_{3} \mathrm{O}_{4}-\mathrm{SnO}_{2}-\mathrm{C}$ decreases to about $5.8 \mathrm{~nm}$ and the pore size distribution shifted to 2.5-20 nm. From the lower total carbon content, higher specific surface area, smaller pore size and narrower pore size distribution described above, it can be inferred that by precipitating two kinds of MO NPs in different shapes layer-by-layer, not only mesoporous nanocarbon but also numerous nano pores formed among the $\mathrm{Fe}_{3} \mathrm{O}_{4}$ and $\mathrm{SnO}_{2} \mathrm{NPs}$ inside the hybrid nanosheets, which is expected to be highly favorable for lithium ion diffusion and electron transfer, thus promising for further enhancing the electrochemical properties of the composite.

Lithium storage properties of the samples as an anode material for LIBs were investigated. Fig. 5 presents the initial discharge/charge curves and cycling performances of the as-prepared samples at a current density of $200 \mathrm{~mA} \mathrm{~g}^{-1}$ in the voltage window of $0.010-3.0 \mathrm{~V}$. In the first 
discharge process, all the samples display a voltage flat of about $0.68 \mathrm{~V}$ as shown in Fig. 5a, which could be attributed to the reduction of $\mathrm{Fe}_{3} \mathrm{O}_{4}$. The $\mathrm{rGO}-\mathrm{Fe}_{3} \mathrm{O}_{4}-\mathrm{C}, \mathrm{rGO}-\mathrm{Fe}_{3} \mathrm{O}_{4}-\mathrm{SnO}_{2}$ and rGO-Fe $\mathrm{O}_{4}-\mathrm{SnO}_{2}-\mathrm{C}$ hybrids deliver discharge specific capacities of 1668.9 , 1927.6, and 1243.6 $\mathrm{mA} \mathrm{h} \mathrm{g}^{-1}$ with the coulombic efficiencies of $62.4 \%, 59.5 \%$ and $62.8 \%$, respectively. Compared with that of $\mathrm{rGO}-\mathrm{Fe}_{3} \mathrm{O}_{4}-\mathrm{C}$ and $\mathrm{rGO}-\mathrm{Fe}_{3} \mathrm{O}_{4}-\mathrm{SnO}_{2}$, the low discharge capacity of rGO-Fe $\mathrm{O}_{4}-\mathrm{SnO}_{2}-\mathrm{C}$ in the first cycle implies that the electrode did not fully uptake $\mathrm{Li}$, as the electrolyte did not completely infiltrate the multi-layer mesoporous nanosheets before electrochemical activation. As shown in the $\mathrm{SEM}$ and TEM images, the $\mathrm{Fe}_{3} \mathrm{O}_{4}$ and $\mathrm{SnO}_{2}$ nanoparticles were closely packed inside the nanosheets, which might be hard for charge transport and electrolyte penetration before electrochemical activation. The irreversible capacity loss in the first cycling process could be attributed to irreversible transformation from $\mathrm{SnO}_{2}$ to $\mathrm{Sn}$ as illustrated in equ. 2 [46]. Besides, the formation of insulating $\mathrm{Li}_{2} \mathrm{O}$ matrix and decomposition of electrolyte along with the formation of solid electrolyte interface (SEI) films are also responsible $[47,48]$, which prevent the fully uptake of Li into the negative electrodes. As the discharge/charge cycling carried on, the $\mathrm{rGO}-\mathrm{Fe}_{3} \mathrm{O}_{4}-\mathrm{SnO}_{2}$ exhibited a fast and continuous decay of the lithium storage capability along with the cycling, which delivered a discharge specific capacity of $581.3 \mathrm{~mA} \mathrm{~g}^{-1}$ at the 100 th cycle, with a capacity fading of $6.73 \mathrm{~mA} \mathrm{~h} \mathrm{~g}^{-1}$ per cycle on average. Without amorphous nanocarbon encapsulated, the cyclical volume changes of MO NPs can generate significant stresses in the electrode material, forming cracks and breakages in electrical conductive pathway. On the other hand, the $\mathrm{rGO}-\mathrm{Fe}_{3} \mathrm{O}_{4}-\mathrm{C}$ showed excellent cycling stability with almost no capacity fading after ten cycles of electrochemical activation. However, because of the low reversible discharge specific capacity of $661.1 \mathrm{~mA} \mathrm{~g}^{-1}$ at the second cycle, it can only maintain a stable discharge specific capacity of $516.2 \mathrm{~mA} \mathrm{~g}^{-1}$ even after a slight increase of $0.95 \mathrm{mAh} \mathrm{g}^{-1}$ per cycle on average since the 30 th cycles. As for the $\mathrm{rGO}-\mathrm{Fe}_{3} \mathrm{O}_{4}-\mathrm{SnO}_{2}-\mathrm{C}$, it displayed a medium high discharge capacity in the initial cycles and exhibited a slow and constant reversible capacity increase along with the cycling. As shown in Fig. 5c, it delivered discharge specific capacities of 1243.6, 819.8, 730.3, 746.2 and 868.6 $\mathrm{mAh} \mathrm{g}^{-1}$ in the first, second, 10th, 50th and 100th cycle, 
respectively, with a capacity increase of $1.54 \mathrm{mAh} \mathrm{g}^{-1}$ per cycle on average since the 10th cycle. Along with the electrochemical activation, the coulombic efficiency was effectively improved from $62.8 \%$ of the first cycle to $100.0 \%$ of the 100 th cycle. The behaviors of capacity increase were also reported by other researchers in $\mathrm{C}_{1}-\mathrm{MO}-\mathrm{C}_{2}$ systems due to the dramatical synergic effect of the components. ${ }^{35,38}$ The higher lithium storage properties of $\mathrm{rGO}-\mathrm{Fe}_{3} \mathrm{O}_{4}-\mathrm{SnO}_{2}-\mathrm{C}$ hybrids could be attributed to the hierarchical sandwiched structure, which thoroughly encapsulates both $\mathrm{Fe}_{3} \mathrm{O}_{4}$ and $\mathrm{SnO}_{2}$ NPs inside the nanosheets. The rGO nanosheets provided good electronic conductivity and buffering effect to some extent. The intact and robust protection by amorphous carbon could prevent the interlayer MO NPs from dropping off from the 2D networks during the discharge/charge processes. Meanwhile, the numerous nanopores produced by layer-by-layer packing of $\mathrm{Fe}_{3} \mathrm{O}_{4}$ and $\mathrm{SnO}_{2}$ NPs provided greenways for the buffering of volume changes during cycling. In addition, the omnidirectional nanocarbon coating layer could inhibit the direct contact between MO NRs and electrolyte to reduce the amount of irreversible SEI films, leading to high coulombic efficiency.

The rate capability of the $\mathrm{rGO}-\mathrm{Fe}_{3} \mathrm{O}_{4}-\mathrm{SnO}_{2}-\mathrm{C}$ mesoporous nanosheets was measured at various current densities as an important parameter for lithium ion batteries. As shown in Fig. 6a and $6 \mathrm{~b}$, the $\mathrm{rGO}-\mathrm{Fe}_{3} \mathrm{O}_{4}-\mathrm{SnO}_{2}-\mathrm{C}$ delivered discharge specific capacities of $871.5,739.1,654.3$, 576.0, 546.1, 503.3, 472.3 and 414.7 $\mathrm{mAh} \mathrm{g}^{-1}$ at current densities of 100, 200, 400, 600, 800, 1000, 1500 and $2000 \mathrm{~mA} \mathrm{~g}^{-1}$, respectively. The cycling performance of $\mathrm{rGO}-\mathrm{Fe}_{3} \mathrm{O}_{4}-\mathrm{SnO}_{2}-\mathrm{C}$ showed excellent stability and similar capacity boosting effect was also observed even at high current densities. When the current density is decreased from 2000 to $100 \mathrm{mAh} \mathrm{g}^{-1}$, the discharge capacity quickly increases back to $869.6 \mathrm{mAh} \mathrm{g}^{-1}$ as it returns to $100 \mathrm{mAh} \mathrm{g}^{-1}$. As a consequence, the $\mathrm{rGO}-\mathrm{Fe}_{3} \mathrm{O}_{4}-\mathrm{SnO}_{2}-\mathrm{C}$ nanosheets are promising for stable operation at various current densities.

To gain insight into the electrochemical reaction kinetics of different electrodes, electrochemical impedances of the samples were measured and the spectra are given in Fig. 7a and $7 \mathrm{~b}$ in the form of the Nyquist plot. The impedance spectrum of each sample is comprised of one compressed semicircle in the high-frequency region and a straight line in the low frequency region. 
The $R_{\mathrm{ct}}$ of $\mathrm{rGO}-\mathrm{Fe}_{3} \mathrm{O}_{4}-\mathrm{SnO}_{2}$ is smaller than that of $\mathrm{rGO}-\mathrm{Fe}_{3} \mathrm{O}_{4}-\mathrm{C}$ as shown in Fig. 7a. It was reported that benefiting from the formation of metallic $(\mathrm{Sn})$ nanograins on the surface of iron oxide NPs, which enhanced the electronic conductivity, the $R_{\mathrm{ct}}$ of iron oxide and tin oxide hybrids was found to be significantly reduced. ${ }^{32}$ However, the $R_{\mathrm{ct}}$ of $\mathrm{rGO}-\mathrm{Fe}_{3} \mathrm{O}_{4}-\mathrm{SnO}_{2}-\mathrm{C}$ is much lower than that of $\mathrm{rGO}-\mathrm{Fe}_{3} \mathrm{O}_{4}-\mathrm{SnO}_{2}$, indicating the omnidirectional nanocarbon is effective to enhanced the electronic conductivity of the entire hybrid material. In addition, the electrochemical impedance spectra of $\mathrm{rGO}-\mathrm{Fe}_{3} \mathrm{O}_{4}-\mathrm{SnO}_{2}-\mathrm{C}$ before and after cycles are given in Fig. 7b. The results show that the $R_{\mathrm{ct}}$ is as high as $2200 \mathrm{U}$ before cycles. This is mainly because the poor conductivity of $\mathrm{SnO}_{2}$ and the electrolyte had not infiltrated into the multi-layer nanosheets. However, it dramatically decreased to $27 \Omega$ only after 3 cycles of electrochemical activation, indicating the formation of conductive metallic $\left(\mathrm{M}^{0}\right)$ nanograins and the infiltration of electrolyte. The plot obtained after 100 cycles almost overlapped with the one obtained after 50 cycles, which implies the structural stability of the material during the reversible Li-ion uptake/release process. It is worth noting that the highly porous structure of the total electrode can also contribute to the improved electrochemical reaction kinetics by providing more active sites for Li storage and numerous channels for rapid electrolyte diffusion, resulting in not only better cyclability but enhanced rate capability as well. It should also be mentioned that although the formation of Sn nanograins could enhance the electronic conductivity of the samples, the amount of $\mathrm{SnO}_{2} \mathrm{NPs}$ should be controlled because it could also affect the cycling performance (Fig. S2). Finally, the TEM images of rGO- $\mathrm{Fe}_{3} \mathrm{O}_{4}-\mathrm{SnO}_{2}-\mathrm{C}$ before and after 100 cycles of discharge/charge process at $200 \mathrm{~mA} \mathrm{~g}^{-1}$ are shown in Fig. 7c and 7d. Except for the electrochemical agglomeration of the $\mathrm{Fe}_{3} \mathrm{O}_{4}$ and $\mathrm{SnO}_{2} \mathrm{NPs}$ and the formation of SEI films on the surface of the hybrid nanosheet, there is only marginal change in its microstructure even after charge and discharge for 100 cycles, indicating high structural stability of the electrode and accounting for the superior cyclability of the electrode. 


\section{Conclusions}

In summary, $\mathrm{rGO}-\mathrm{Fe}_{3} \mathrm{O}_{4}-\mathrm{SnO}_{2}-\mathrm{C}$ quaternary hybrid nanosheets were successfully synthesized via layer-by-layer homogeneous precipitations followed by a solvothermal treatment. The rGO support, $\mathrm{Fe}_{3} \mathrm{O}_{4}$ and $\mathrm{SnO}_{2} \mathrm{NPs}$, and amorphous carbon were uniformly simultaneously combined to form a sandwich-like buffering structure with nanopores in an average size of $5.8 \mathrm{~nm}$. Due to the structural stability of the composites and the synergistic effects of the components inside the nanosheets, the $\mathrm{rGO}-\mathrm{Fe}_{3} \mathrm{O}_{4}-\mathrm{SnO}_{2}-\mathrm{C}$ nanosheets exhibited an improved capacity of $868.6 \mathrm{mAh} \mathrm{g}^{-1}$ after 100 cycles at $200 \mathrm{~mA} \mathrm{~g}^{-1}$ and excellent cycling stability with an increase of $1.54 \mathrm{~mA} \mathrm{~h} \mathrm{~g}^{-1}$ per cycle since the 10th cycle. Furthermore, the composite showed excellent stability and capacity boosting effect even at high rates, delivering a reversible capacity of $414.7 \mathrm{mAh} \mathrm{g}^{-1}$ at a current density of $2.0 \mathrm{~A} \mathrm{~g}^{-1}$, demonstrating its potential as a promising hybrid material for high performance lithium ion batteries.

\section{Acknowledgement}

This research was financial supported by the Guangdong Natural Science Foundation (grant No. 9151064201000039), the Guangdong Science and Technology Planning Project (No. 2009B010900025), the National Natural Science Foundation of China (Nos. 51003034 and 21173088), the Key Academic Program of the 3rd phase '211 Project' (No. 2009B010100001), the President of South China Agricultural University (No. K09140), the State Key Laboratory of Motor Vehicle Biofuel Technology (No. 2013025), and the Air Force Office of Scientific Research (No. FA9550-12-1-0159). 


\section{References}

[1] C. Capasso, O. Veneri, Experimental analysis on the performance of lithium based batteries for road full electric and hybrid vehicles, Appl. Energ. 136 (2014) 921.

[2] R. Van Noorden, A better battery, Nature 507 (2014) 26.

[3] A.L.M. Reddy, S.R. Gowda, M.M. Shaijumon, P.M. Ajayan, Hybrid nanostructures for energy storage applications, Adv. Mater. 24 (2012) 5045.

[4] H.T. Zhang, X.Z. Sun, X. Zhang, H. Lin, W. Kai, Y. Ma, High-capacity nanocarbon anodes for lithium-ion batteries, J. Alloys Comp. 622 (2015) 783.

[5] S.X. Wang, L.P. Yang, L.P. Stubbs, X. Li, C.B. He, Lignin-derived fused electrospun carbon fibrous mats as high performance anode materials for lithium ion batteries, ACS Appl. Mater. Interfaces 5 (2013) 12275.

[6] L. Xiao, D.Q. Wu, S. Han, Y.S. Huang, S. Li, M.Z. He, F. Zhang, X.L. Feng, Self-assembled $\mathrm{Fe}_{2} \mathrm{O}_{3}$ /graphene aerogel with high lithium storage performance, ACS Appl. Mater. Interfaces 5 (2013) 3764.

[7] L. Chen, H.Y. Xu, L.E. Li, F.F. Wu, J. Yang, Y.T. Qian, A comparative study of lithium-storage performances of hematite: nanotubes vs. nanorods, J. Power Sources 245 (2014) 429.

[8] L. Noerochim, J.Z. Wang, S.L. Chou, D. Wexler, H.K. Liu, Free-standing single-walled carbon nanotube/ $\mathrm{SnO}_{2}$ anode paper for flexible lithium-ion batteries, Carbon 50 (2012) 1289.

[9] H.K. Zhang, H.H. Song, X.H. Chen, J.S. Zhou, H.J. Zhang, Preparation and electrochemical performance of $\mathrm{SnO}_{2} @$ carbon nanotube core-shell structure composites as anode material for lithium-ion batteries, Electrochim. Acta 59 (2012) 160.

[10] S. Luo, H.C. Wu, Y. Wu, K.L. Jiang, J.P. Wang, S.S. Fan, $\mathrm{Mn}_{3} \mathrm{O}_{4}$ nanoparticles anchored on continuous carbon nanotube network as superior anodes for lithium ion batteries, J. Power Sources 249 (2014) 463.

[11] S.K. Park, A.H. Jin, S.H. Yu, J. Ha, B. Jang, S. Bong, S. Woo, Y.E. Sung, Y.Z. Piao, In situ hydrothermal synthesis of $\mathrm{Mn}_{3} \mathrm{O}_{4}$ nanoparticles on nitrogen-doped graphene as 
high-performance anode materials for lithium ion batteries, Electrochim. Acta 120 (2014) 452.

[12] D.H. Ge, H.B. Geng, J.Q. Wang, J.W. Zheng, Y. Pan, X.Q. Cao, H.W. Gu, Porous nano-structured $\mathrm{Co}_{3} \mathrm{O}_{4}$ anode materials generated from coordination-driven self-assembled aggregates for advanced lithium ion batteries, Nanoscale 6 (2014) 9689.

[13] Y.N. Huang, C.C. Chen, C.H. An, C.C. Xu, Y.N. Xu, Y.J. Wang, L.F. Jiao, H.T. Yuan, Synthesis of cobalt based complexes and conversion to $\mathrm{Co}_{3} \mathrm{O}_{4}$ nanoparticles as a high performance anode for lithium ion battery, Electrochim. Acta 145 (2014) 34.

[14] J. Liu, X. W. Liu, Two-dimensional nanoarchitectures for lithium storage, Adv. Mater. 24 (2012) 4097.

[15] H.B. Wu, J.S. Chen, H.H. Hng, X.W. Lou, Nanostructured metal oxide-based materials as advanced anodes for lithium-ion batteries, Nanoscale 4 (2012) 2526.

[16] G.M. Zhou, D.W. Wang, F. Li, L.L. Zhang, N. Li, Z.S. Wu, L. Wen, G.Q. Lu, H.M Cheng, Graphene-wrapped $\mathrm{Fe}_{3} \mathrm{O}_{4}$ anode material with improved reversible capacity and cyclic stability for lithium ion batteries, Chem. Mater. 22 (2010) 5306.

[17] M.S. Park, Y.M. Kang, G.X. Wang, S.X. Dou, H.K. Liu, The effect of morphological modification on the electrochemical properties of $\mathrm{SnO}_{2}$ nanomaterials, Adv. Funct. Mater. 18 (2008) 455 .

[18] I.A. Courtney, W.R. McKinnon, J.R. Dahn, On the aggregation of tin in SnO composite glasses caused by the reversible reaction with lithium, J. Electrochem. Soc. 146 (1999) 59.

[19] S. Denis, E. Baudrin, M. Touboul, J.M. Tarascon, Synthesis and electrochemical properties of amorphous vanadates of general formula $\mathrm{RVO}_{4}(\mathrm{R}=\mathrm{In}, \mathrm{Cr}, \mathrm{Fe}, \mathrm{Al}, \mathrm{Y})$ vs. $\mathrm{Li}, \mathrm{J}$. Electrochem. Soc. 144 (1997) 4099 .

[20] W.M. Zhang, X.L. Wu, J.S. Hu, Y.G. Guo, L.J. Wan, Carbon coated $\mathrm{Fe}_{3} \mathrm{O}_{4}$ nanospindles as a superior anode material for lithium-ion batteries, Adv. Funct. Mater. 18 (2008) 3941.

[21] X.W. Lou, Y. Wang, C.L. Yuan, J.Y. Lee, L.A. Archer, A. template-free synthesis of $\mathrm{SnO}_{2}$ hollow nanostructures with high lithium storage capacity, Adv. Mater. 18 (2006) 2325. 
[22] J.S. Chen, X.W. Lou, $\mathrm{SnO}_{2}$-based nanomaterials: Synthesis and application in lithium-ion batteries, Small 9 (2013) 1877.

[23] J. Jiang, Y.Y. Li, J.P. Liu, X.T. Huang, C.Z. Yuan, X.W. Lou, Recent advances in metal oxide-based electrode architecture design for electrochemical energy stroage, Adv. Mater. 24 (2012) 5166 .

[24] A.S. Arico, P. Bruce, B. Scrosati, J.M. Tarascon, W. Van Schalkwijk, Nanostructured materials for advanced energy conversion and storage devices, Nat. Mater. 4 (2005) 366.

[25] L. Pan, X.D. Zhu, X.M. Xie, Y.T. Liu, Smart hybridization of $\mathrm{TiO}_{2}$ nanorods and $\mathrm{Fe}_{3} \mathrm{O}_{4}$ nanoparticles with pristine graphene nanosheets: hierarchically nanoengineered ternary heterostructures for high-Rate lithium storage, Adv. Funct. Mater. 25 (2015) 3341.

[26] Y. Zhao, J.X. Li, C.X. Wu, Y.H. Ding, L.H. Guan, A yolk-shell $\mathrm{Fe}_{3} \mathrm{O}_{4} @ \mathrm{C}$ composite as an anode material for high-Rate lithium batteries, ChemPlusChem 77 (2012) 748.

[27] X.D. Zhu, K.X. Wang, D.J. Yan, S.R. Le, R.J. Ma, K.N. Sun, Y.T. Liu, Creating a synergistic interplay between tubular $\mathrm{MoS}_{2}$ and particulate $\mathrm{Fe}_{3} \mathrm{O}_{4}$ for improved lithium storage, Chem. Commun. 51 (2015) 11888.

[28] Y.T. Liu, X.D. Zhu, Z.Q. Duan, X.M. Xie, Flexible and robust $\mathrm{MoS}_{2}$-graphene hybrid paper cross-linked by a polymer ligand: a high-performance anode material for thin film lithium-ion batteries, Chem. Commun. 49 (2013) 10305.

[29] X.H. Liu, J. Zhang, W.P. Si, L.X. Xi, S. Oswald, C.L. Yan, O.G. Schmidt, High-rate amorphous $\mathrm{SnO}_{2}$ nanomembrane anodes for Li-ion batteries with a long cycling life, Nanoscale 7 (2015) 282.

[30] L. Pan, X.D. Zhu, X.M. Xie, Y.T. Liu, Delicate ternary heterostructures achieved by hierarchical co-assembly of $\mathrm{Ag}$ and $\mathrm{Fe}_{3} \mathrm{O}_{4}$ nanoparticles on $\mathrm{MoS}_{2}$ nanosheets: morphological and compositional synergy in reversible lithium storage, J. Mater. Chem. A 3 (2015) 2726

[31] X. Gu, L. Chen, Z.C. Ju, H.Y. Xu, J. Yang, Y.T. Qian, Controlled growth of porous $\alpha-\mathrm{Fe}_{2} \mathrm{O}_{3}$ branches on $\beta-\mathrm{MnO}_{2}$ nanorods for excellent performance in lithium-ion batteries, Adv. Funct. Mater. 23 (2013) 4049. 
[32] G.F. Xia, N. Li, D.Y. Li, R.P. Liu, C. Wang, Q. Li, X.J. Lu, J.S. Spendelow, J.L. Zhang, G. $\mathrm{Wu}$, Graphene $/ \mathrm{Fe}_{2} \mathrm{O}_{3} / \mathrm{SnO}_{2}$ ternary nanocomposites as a high-performance anode for lithium ion batteries, ACS Appl. Mater. Interfaces 5 (2013) 8607.

[33] L. Wang, D. Wang, Z.H. Dong, F.X. Zhang, J. Jin, Interface chemistry engineering for stable cycling of reduced $\mathrm{GO} / \mathrm{SnO}_{2}$ nanocomposites for lithium ion battery, Nano Lett. 13 (2013) 1711.

[34] G. Wang, H. Wang, S.B. Cai, J.T. Bai, Z.Y. Ren, J.B. Bai, Synthesis and evaluation of carbon-coated $\mathrm{Fe}_{2} \mathrm{O}_{3}$ loaded on graphene nanosheets as an anode material for high performance lithium ion batteries, J. Power Sources 239 (2013) 37.

[35] D.N. Wang, J.L. Yang, X.F. Li, D.S. Geng, R.Y. Li, M. Cai, T.K. Sham, X.L. Sun, Layer by layer assembly of sandwiched graphene/ $\mathrm{SnO}_{2}$ nanorod/carbon nanostructures with ultrahigh lithium ion storage properties, Energy Environ. Sci. 6 (2013) 2900.

[36] M. Dirican, M. Yanilmaz, K. Fu, Y. Lu, H. Kizil, X.W. Zhang, Carbon-enhanced electrodeposited $\mathrm{SnO}_{2} /$ carbon nanofiber composites as anode for lithium-ion batteries, J. Power Sources 264 (2014) 240.

[37] Z.Y. Wang, D.Y. Luan, S. Madhavi, Y. Hu, X.W. Lou, Assembling carbon-coated a-Fe $\mathrm{F}_{2} \mathrm{O}_{3}$ hollow nanohorns on the CNT backbone for superior lithium storage capability, Energy Environ. Sci. 5 (2012) 5252.

[38] X. Huang, J. Chen, H. Yu, R. Cai, S.J. Peng, Q.Y. Yan, H.H. Hng, Carbon buffered-transition metal oxide nanoparticle-graphene hybrid nanosheets as high-performance anode materials for lithium ion batteries, J. Mater. Chem. A 1 (2013) 6901.

[39] W.S. Hummers, R.E. Offeman, Preparation of graphitic oxide, J. Am. Chem. Soc. 80 (1958) 1339.

[40] D.C. Marcano, D.V. Kosynkin, J.M. Berlin, A. Sinitskii, Z.Z. Sun, A. Slesarev, L.B. Alemany, W. Lu, J.M. Tour, Improved synthesis of graphene oxide, ACS Nano 4 (2010) 4806.

[41] X.F. Li, X.B. Meng, J. Liu, D.S. Geng, Y. Zhang, M.N. Banis, Y.L. Li, J.L. Yang, R.Y. Li, 
X.L. Sun, M. Cai, M.W. Verbrugge, Tin oxide with controlled morphology and crystallinity by atomic layer deposition onto graphene nanosheets for enhanced lithium storage, Adv. Funct. Mater. 22 (2012) 1647.

[42] J.T. Yin, M. Wada, K. Yamamoto, Y. Kitano, S. Tanase, T. Sakai, Micrometer-scale amorphous si thin-film electrodes fabricated by electron-beam deposition for Li-ion batteries, J. Electrochem. Soc. 153 (2006) A 472.

[43] M.X. Chen, C.C. Zhang, X.C. Li, L. Zhang, Y.L. Ma, L. Zhang, X.Y. Xu, F.L. Xia, W. Wang, J.P. Gao, Wang W.; Gao J. P. A One-step method for reduction and self-assembling of graphene oxide into reduced graphene oxide aerogels, J. Mater. Chem. A 1 (2013) 2869.

[44] C. Hu, S. Sedghi, A. Silvestre-Albero, G.G. Andersson, A. Sharma, P. Pendleton, F. Rodríguez-Reinoso, K. Kaneko, M.J. Biggs, Raman spectroscopy study of the transformation of the carbonaceous skeleton of a polymer-based nanoporous carbon along the thermal annealing pathway, Carbon 85 (2015) 147.

[45] Y.W. Zhang, R. Wang, X.D. Lin, Z.H. Wang, J.Z. Liu, J.H. Zhou, K.F. Cen, Catalytic performance of different carbon materials for hydrogen production in sulfur-iodine thermochemical cycle, Appl. Catal. B-Environ. 166-167 (2015) 413.

[46] I.A. Courtney, J.R. Dahn, Electrochemical and In Situ X-Ray Diffraction studies of the reaction of uthium with tin oxide composites, J. Electrochem. Soc. 144 (1997) 2045.

[47] P. Poizot, S. Laruelle, S. Grugeon, L. Dupont, J.M. Tarascon, Searching for new anode materials for the Li-ion technology: Time to deviate from the usual path, J. Power Sources 97-98 (2001) 235.

[48] P. Poizot, S. Laruelle, S. Grugeon, L. Dupont, J.M. Tarascon, Nano-sized transition-metal oxides as negative-electrode materials for lithium-ion batteries, Nature 407 (2000) 496. 


\section{Captions of Figures and Tables}

Table 1 The fitting results and parameters of Raman spectrum of $\mathrm{rGO}-\mathrm{Fe}_{3} \mathrm{O}_{4}-\mathrm{SnO}_{2}-\mathrm{C}$.

Scheme 1 Illustration of procedure for fabricating $\mathrm{rGO}-\mathrm{Fe}_{3} \mathrm{O}_{4}-\mathrm{SnO}_{2}-\mathrm{C}$ mesoporous hybrid nanosheets.

Fig. $1 \mathrm{SEM}$ images of rGO-Fe $\mathrm{O}_{4}-\mathrm{C}(\mathrm{a}), \mathrm{rGO}-\mathrm{Fe}_{3} \mathrm{O}_{4}-\mathrm{SnO}_{2}$ (b) and $\mathrm{rGO}-\mathrm{Fe}_{3} \mathrm{O}_{4}-\mathrm{SnO}_{2}-\mathrm{C}$ (c).

Fig. 2 TEM images of $\mathrm{rGO}-\mathrm{Fe}_{3} \mathrm{O}_{4}-\mathrm{C}(\mathrm{a}), \mathrm{rGO}_{-} \mathrm{Fe}_{3} \mathrm{O}_{4}-\mathrm{SnO}_{2}(\mathrm{~b}), \mathrm{rGO}_{-} \mathrm{Fe}_{3} \mathrm{O}_{4}-\mathrm{SnO}_{2}-\mathrm{C}$ (c) and SEAD image of $\mathrm{rGO}_{-} \mathrm{Fe}_{3} \mathrm{O}_{4}-\mathrm{SnO}_{2}-\mathrm{C}(\mathrm{d})$.

Fig. 3 (a) XRD patterns of $\mathrm{rGO}-\mathrm{Fe}_{3} \mathrm{O}_{4}-\mathrm{C}$, rGO-Fe ${ }_{3} \mathrm{O}_{4}-\mathrm{SnO}_{2}$ and $\mathrm{rGO}-\mathrm{Fe}_{3} \mathrm{O}_{4}-\mathrm{SnO}_{2}-\mathrm{C}$; (b) TG curves of $\mathrm{rGO}-\mathrm{Fe}_{3} \mathrm{O}_{4}-\mathrm{C}, \mathrm{rGO}_{-} \mathrm{Fe}_{3} \mathrm{O}_{4}-\mathrm{SnO}_{2}$ and $\mathrm{rGO}-\mathrm{Fe}_{3} \mathrm{O}_{4}-\mathrm{SnO}_{2}-\mathrm{C}$; (c) Raman spectrum of $\mathrm{rGO}-\mathrm{Fe}_{3} \mathrm{O}_{4}-\mathrm{SnO}_{2}-\mathrm{C}$.

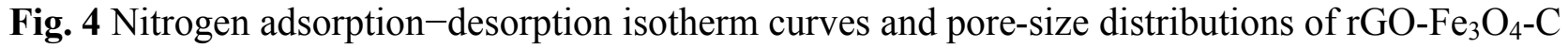
(a) and $\mathrm{rGO}-\mathrm{Fe}_{3} \mathrm{O}_{4}-\mathrm{SnO}_{2}-\mathrm{C}(\mathrm{b})$

Fig. 5 Electrochemical properties of the composites at the current density of $200 \mathrm{~mA} \mathrm{~g}^{-1}$ : (a) Initial discharge/charge curves of the samples; (b) Cycling performance of the samples; (c) Discharge/charge profiles of $\mathrm{rGO}-\mathrm{Fe}_{3} \mathrm{O}_{4}-\mathrm{SnO}_{2}-\mathrm{C}$ in the first, second, 10th, 50th and 100th cycles.

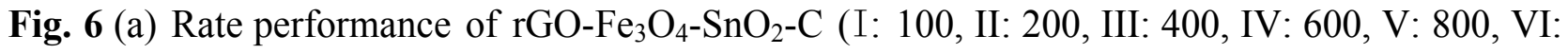
1000, VII: 1500 and VIII: $2000 \mathrm{~mA} \mathrm{~g}^{-1}$ ); (b) Discharge/charge profiles of rGO- $\mathrm{Fe}_{3} \mathrm{O}_{4}-\mathrm{SnO}_{2}-\mathrm{C}$ at various rates.

Fig. 7 Nyquist plots of the three samples after 100 cycles (a) and the $\mathrm{rGO}-\mathrm{Fe}_{3} \mathrm{O}_{4}-\mathrm{SnO}_{2}-\mathrm{C}$ before and after cycles (b); TEM images of $\mathrm{rGO}-\mathrm{Fe}_{3} \mathrm{O}_{4}-\mathrm{SnO}_{2}-\mathrm{C}$ before (c) and after (d) 100 cycles of discharge/charge process at $200 \mathrm{~mA} \mathrm{~g}^{-1}$. 


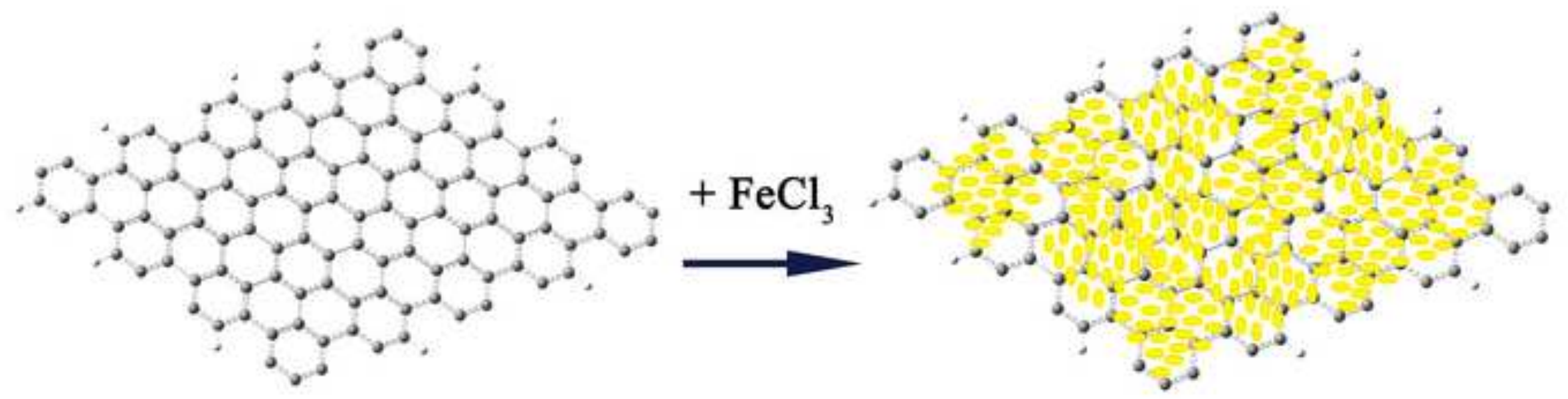

\section{GO}

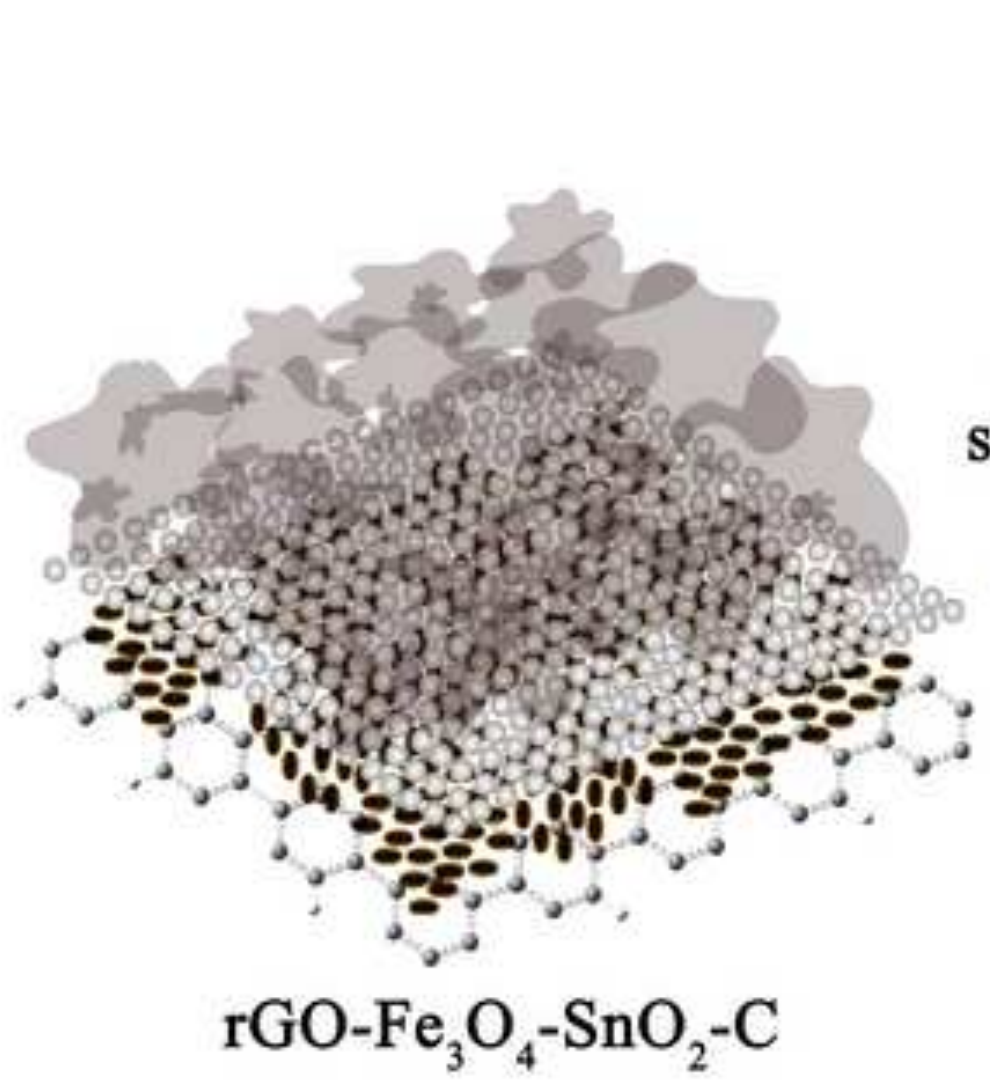

\section{$\mathrm{GO}-\mathrm{FeOOH}$}

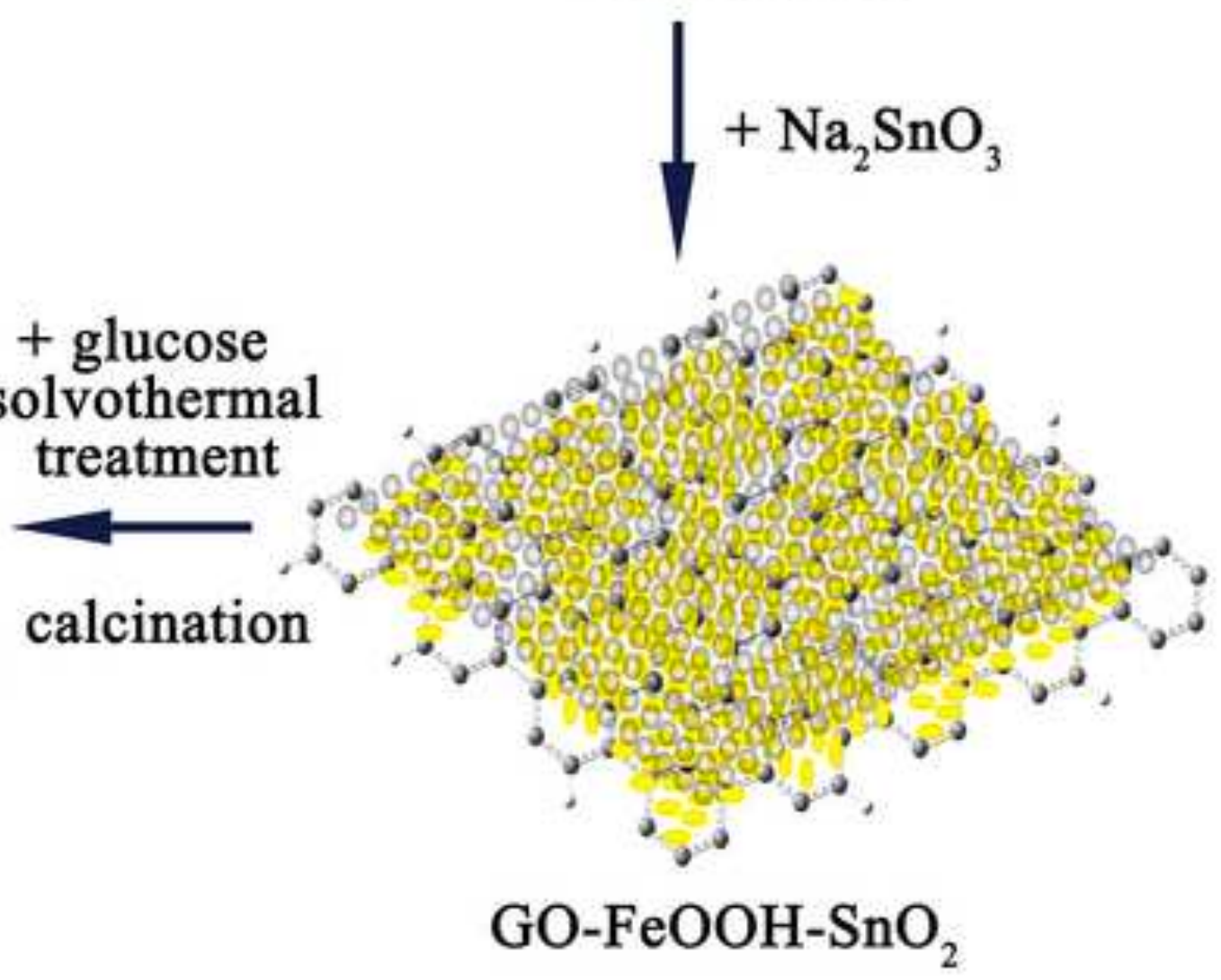




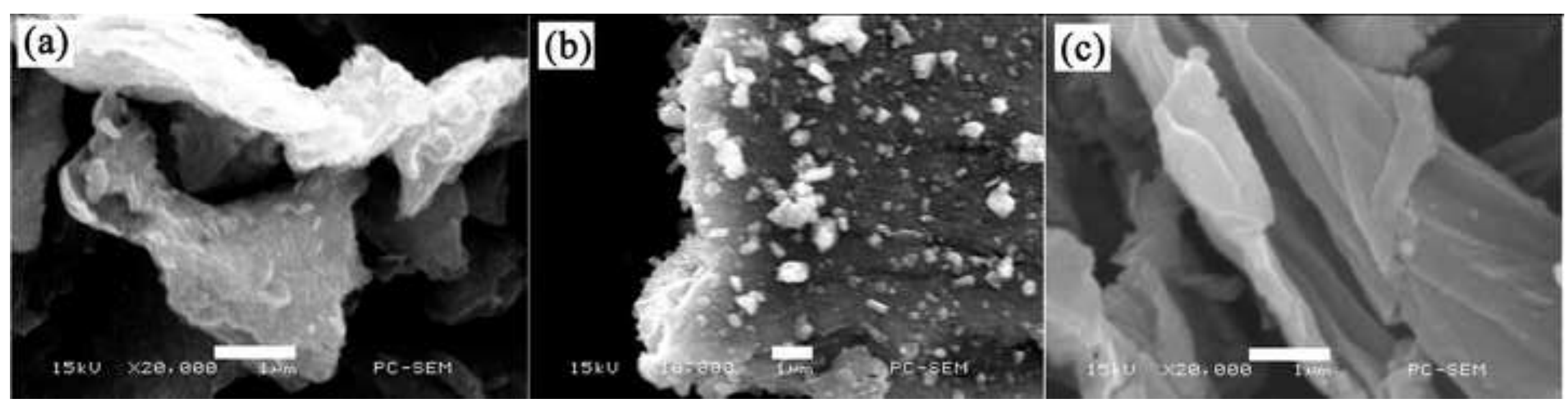

(b)
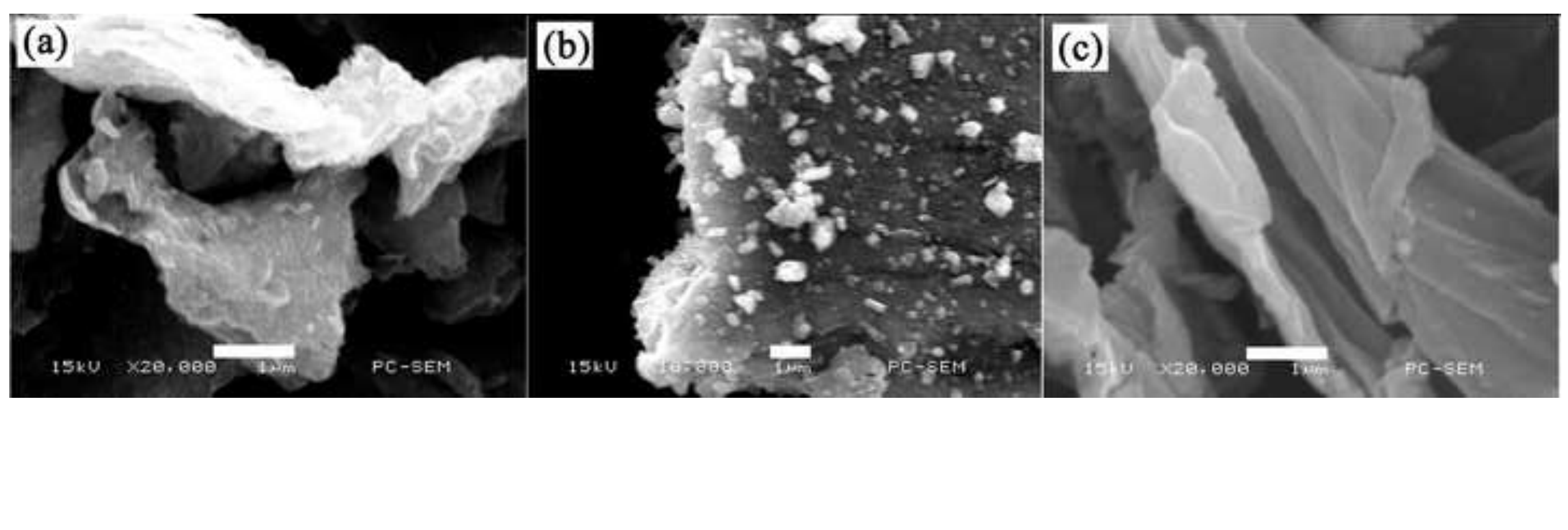


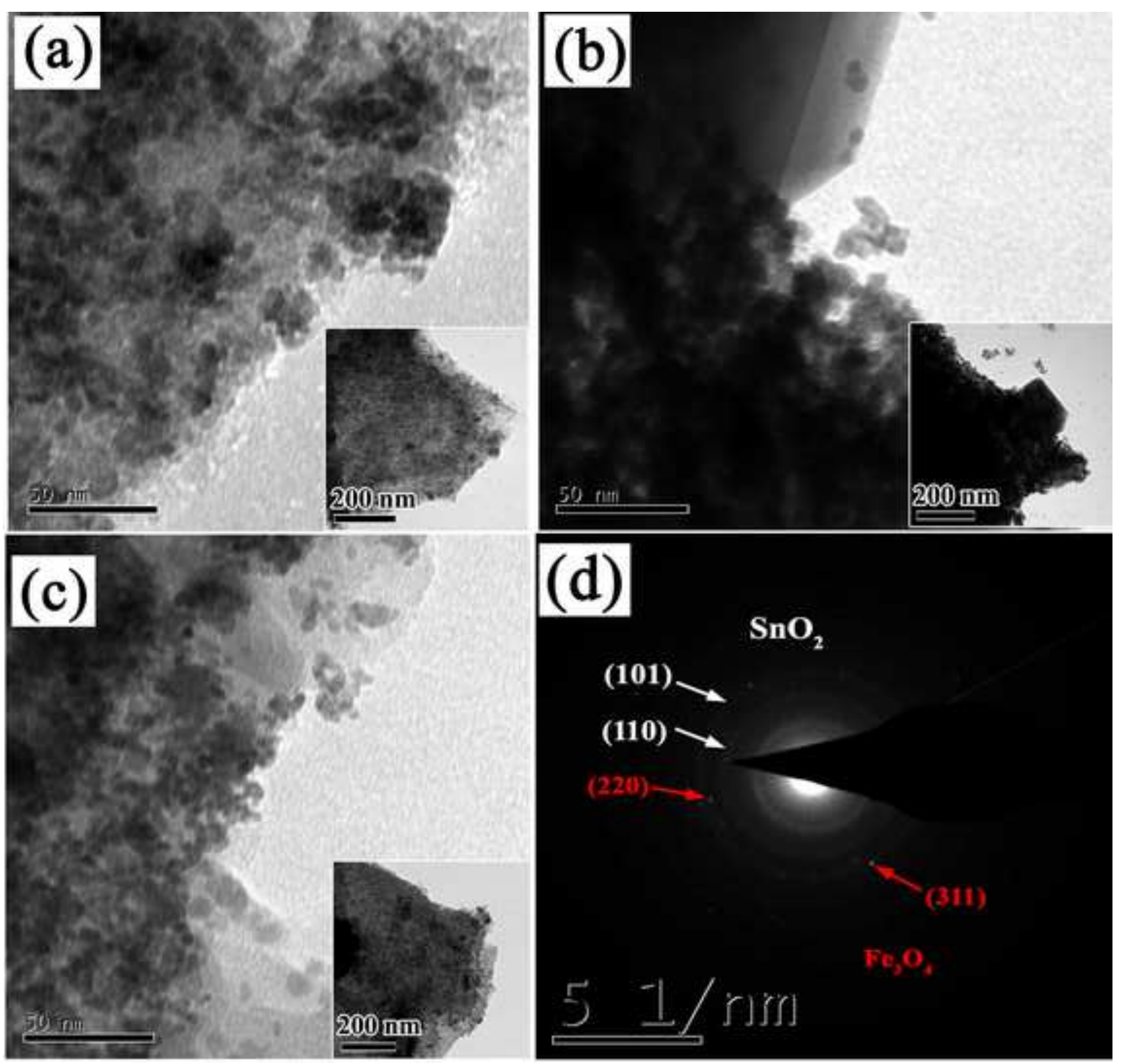



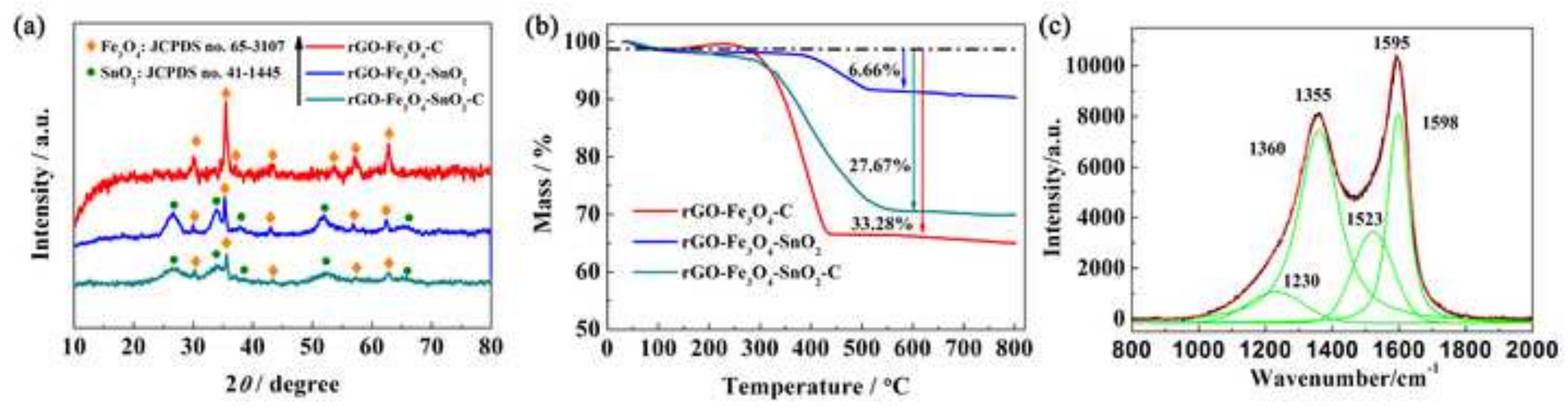
(a)

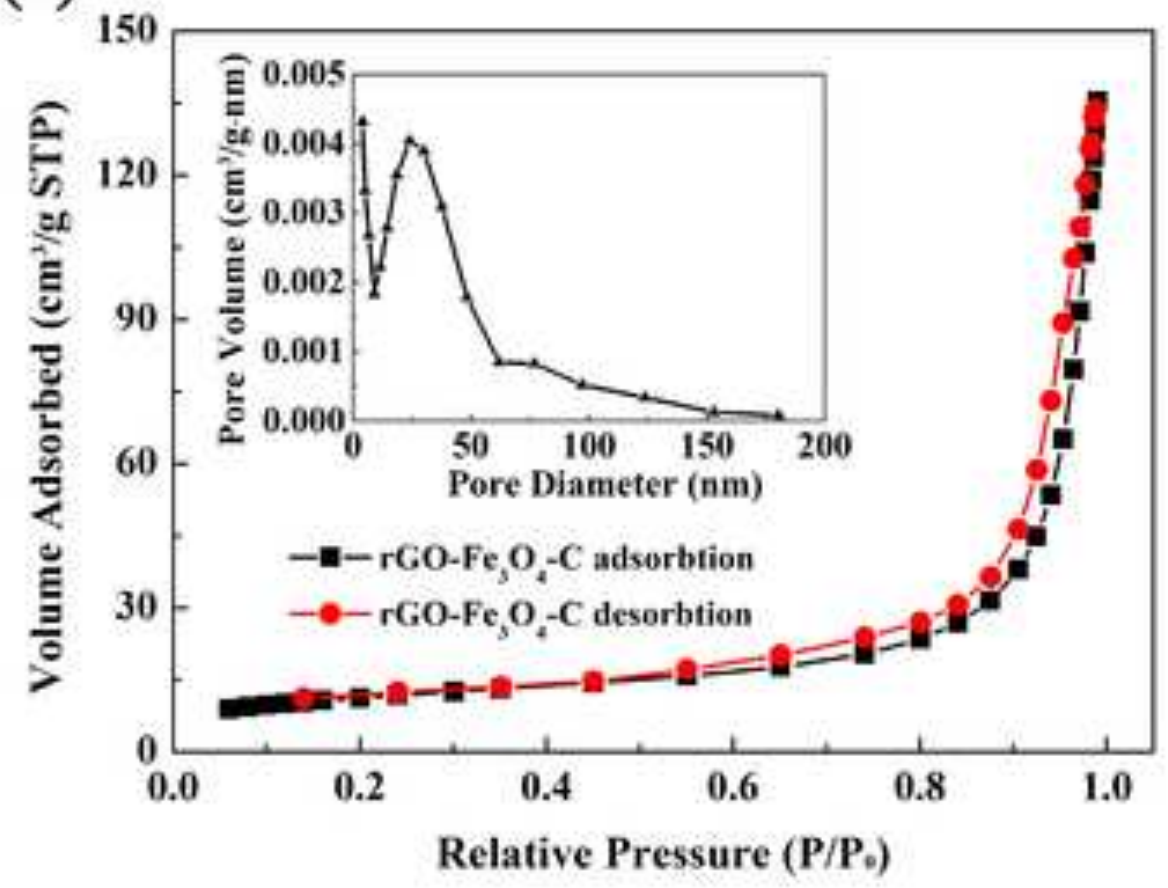

(b)

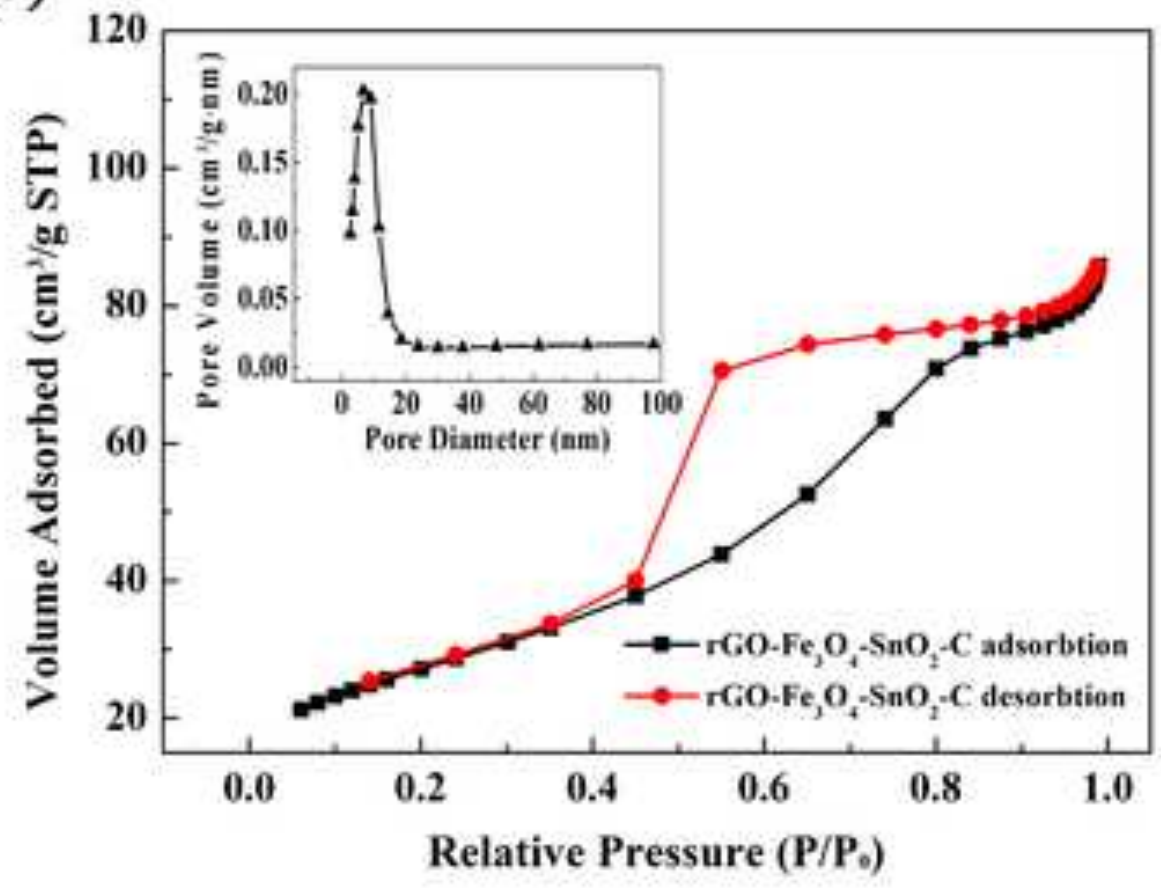


(a)

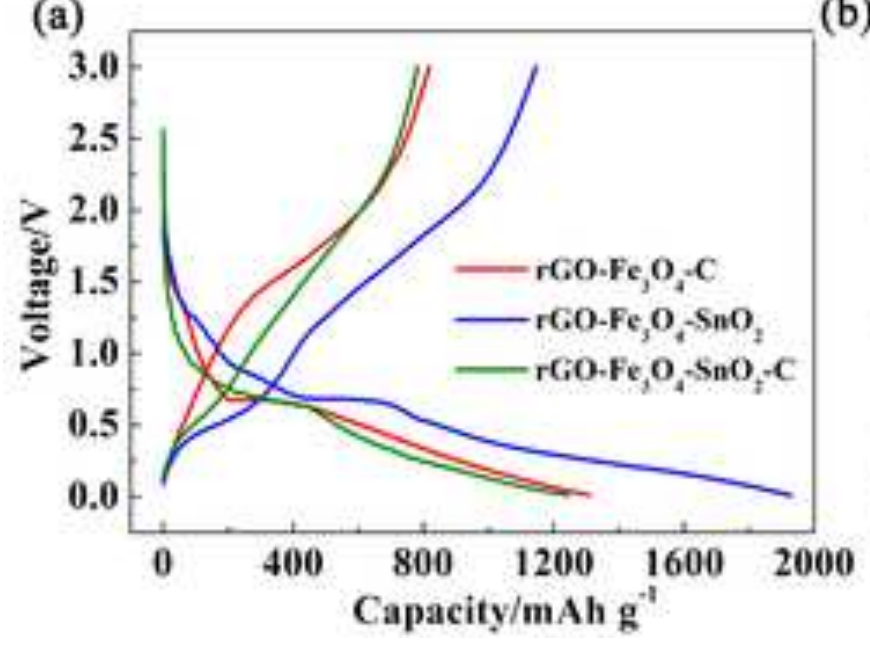

(b)

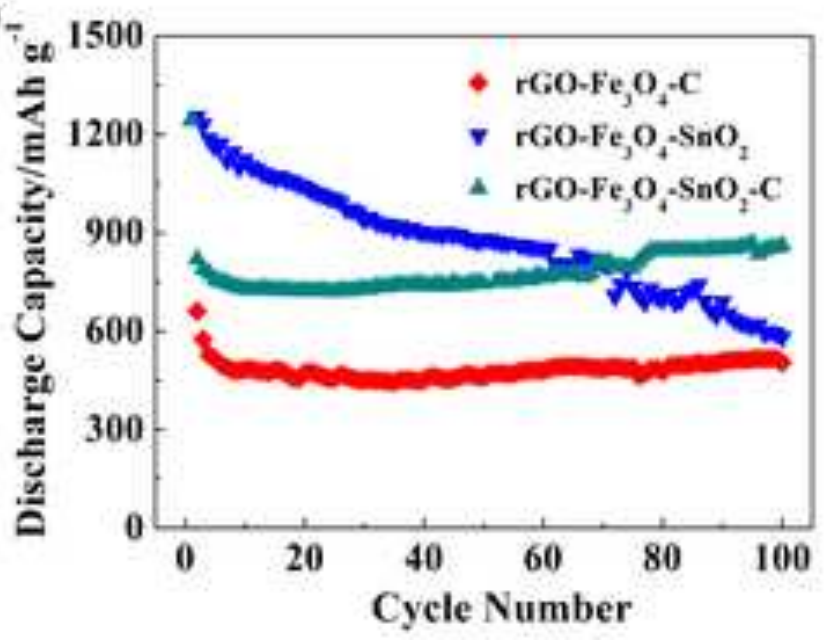

(c)

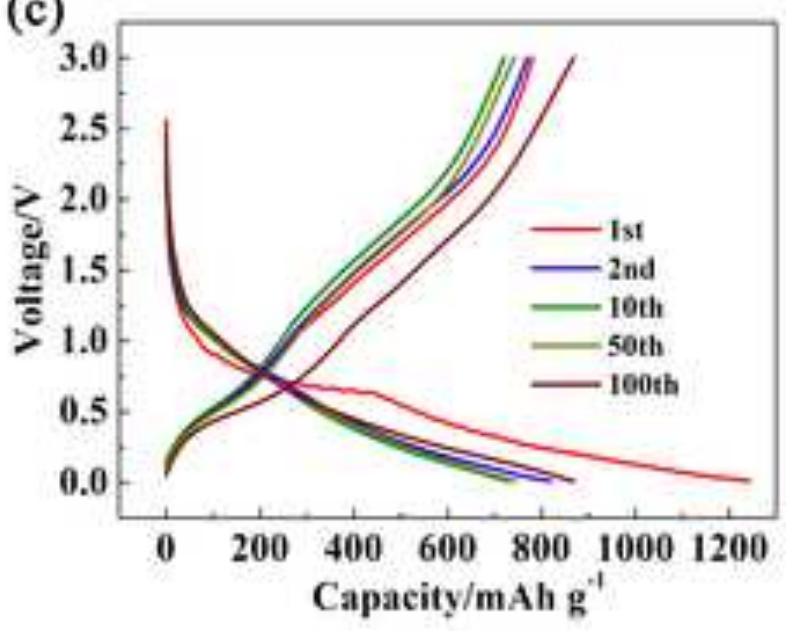


(a)

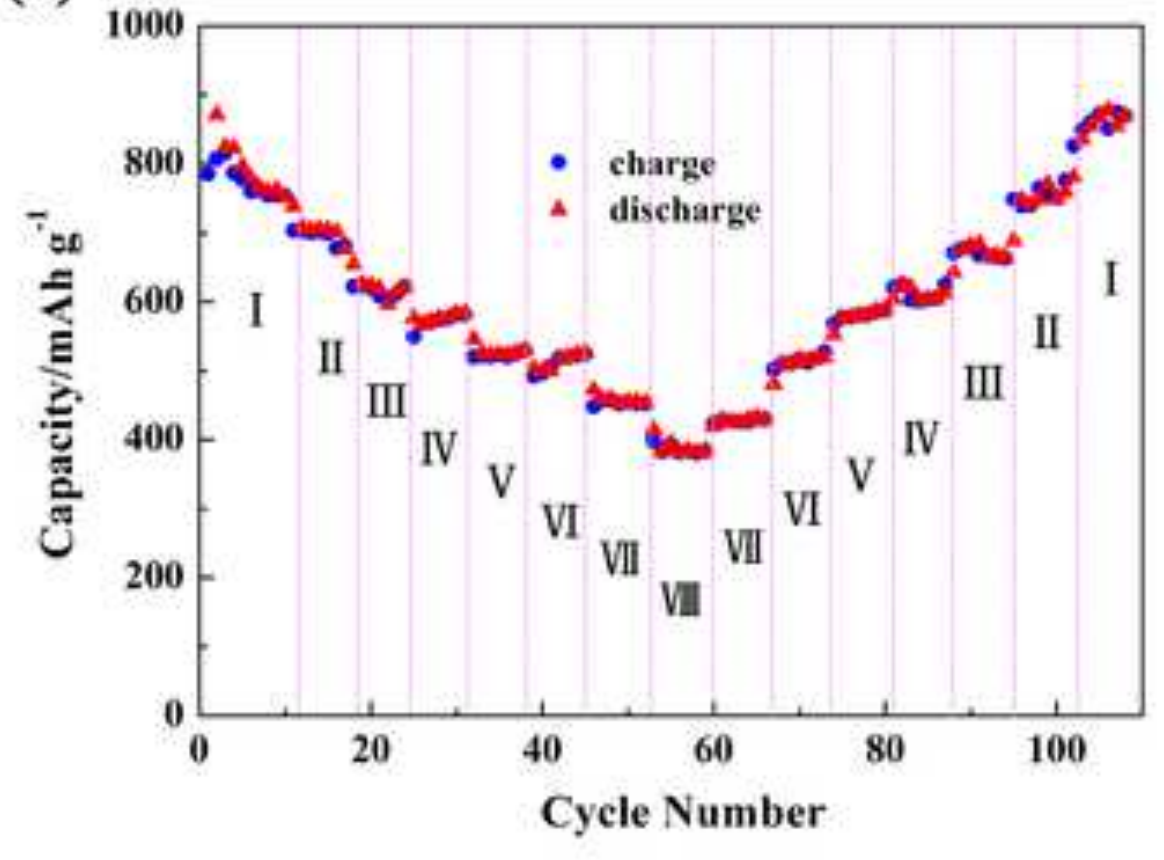

(b)

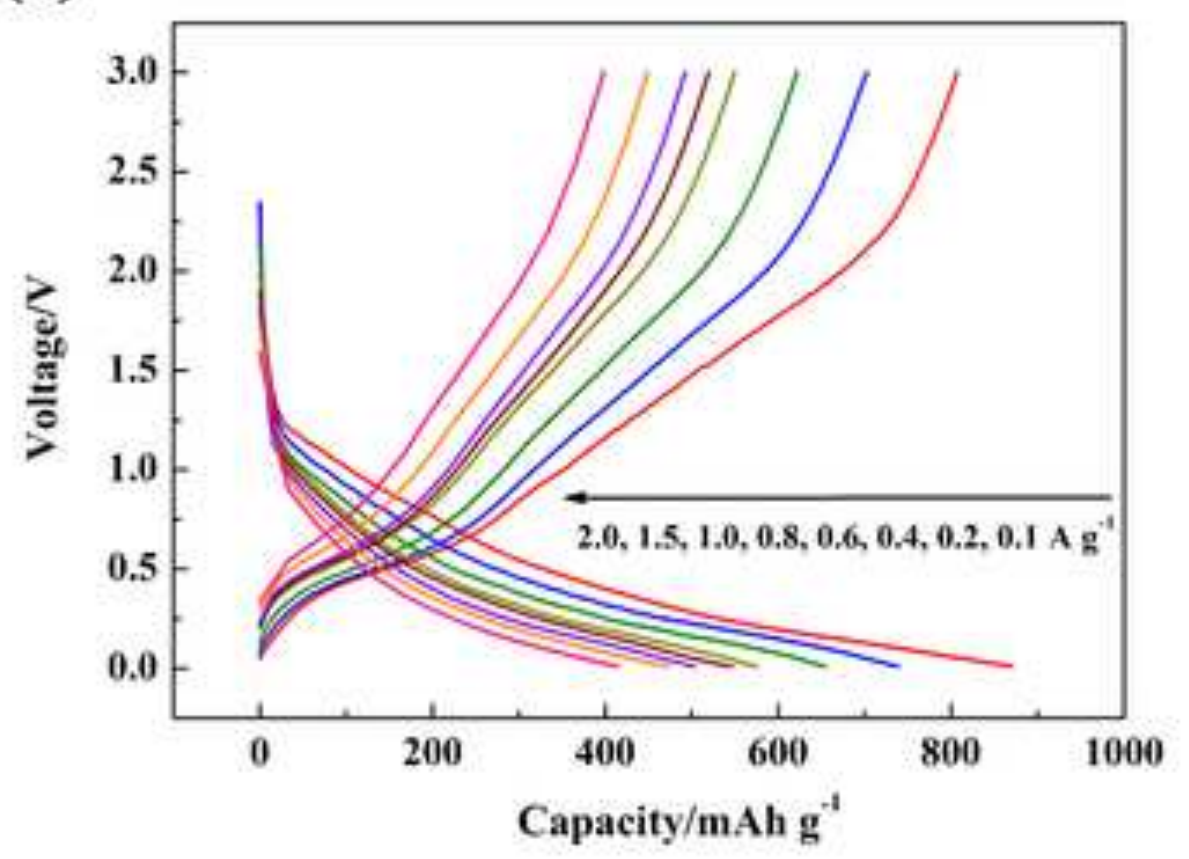


(a)

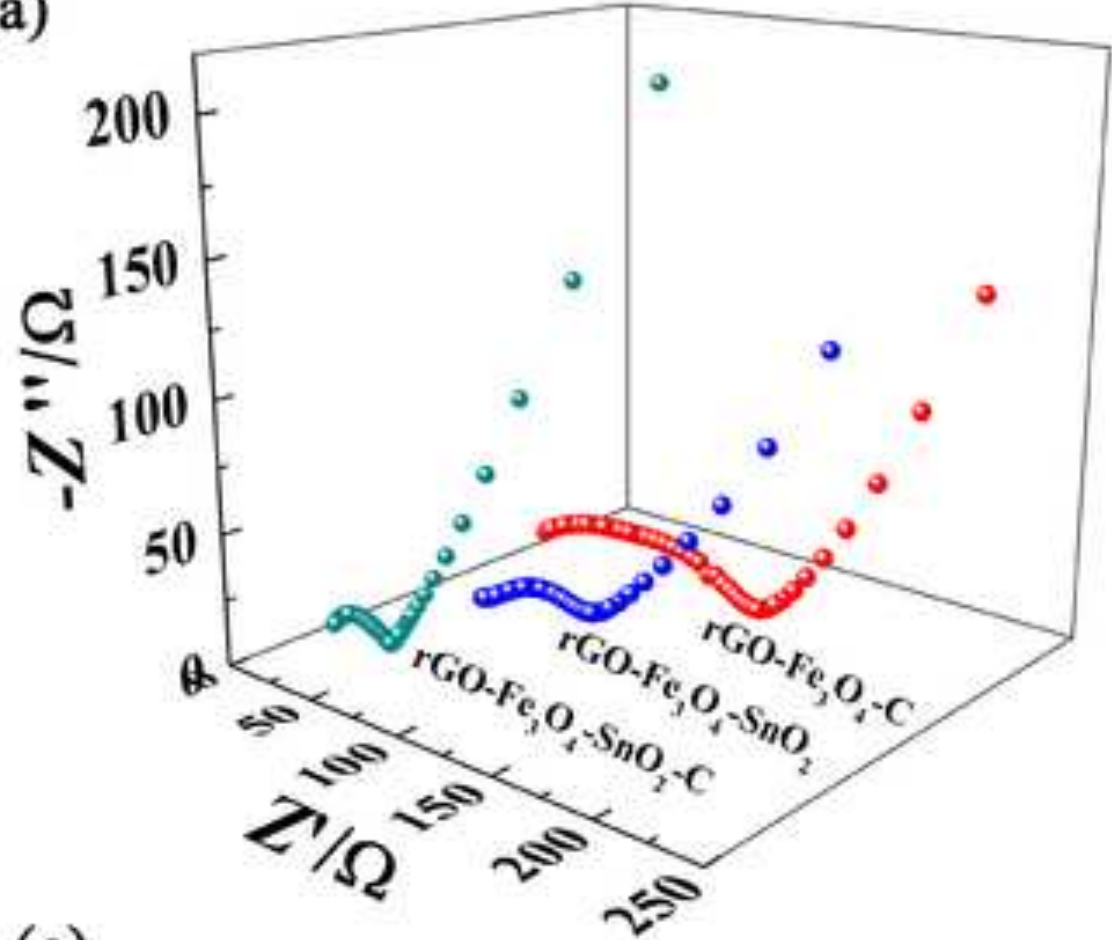

(c)

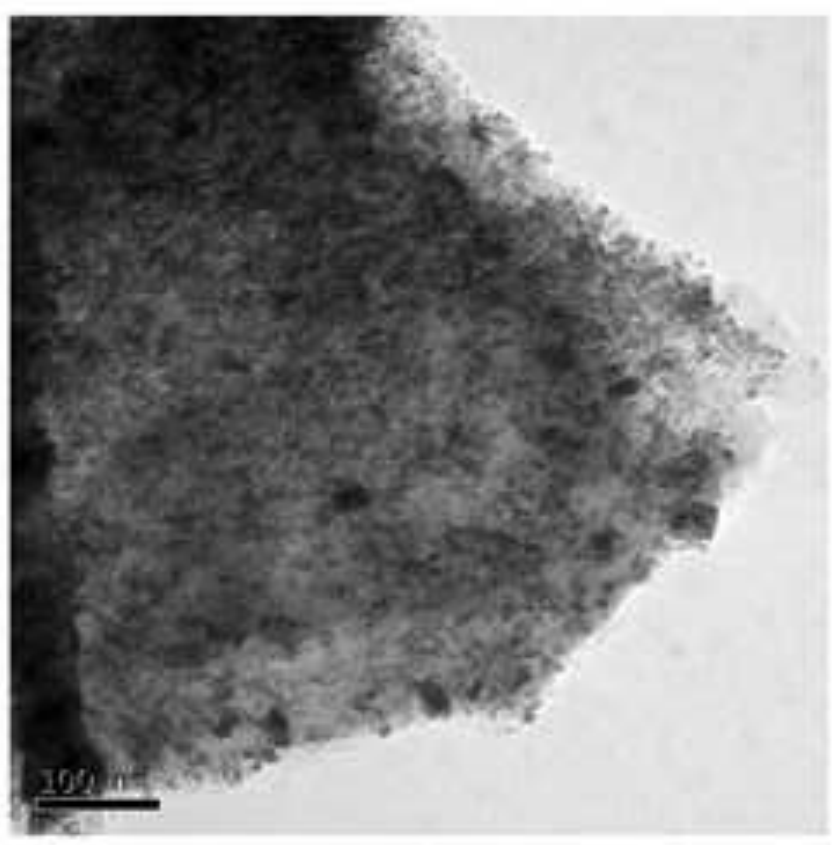

(b)
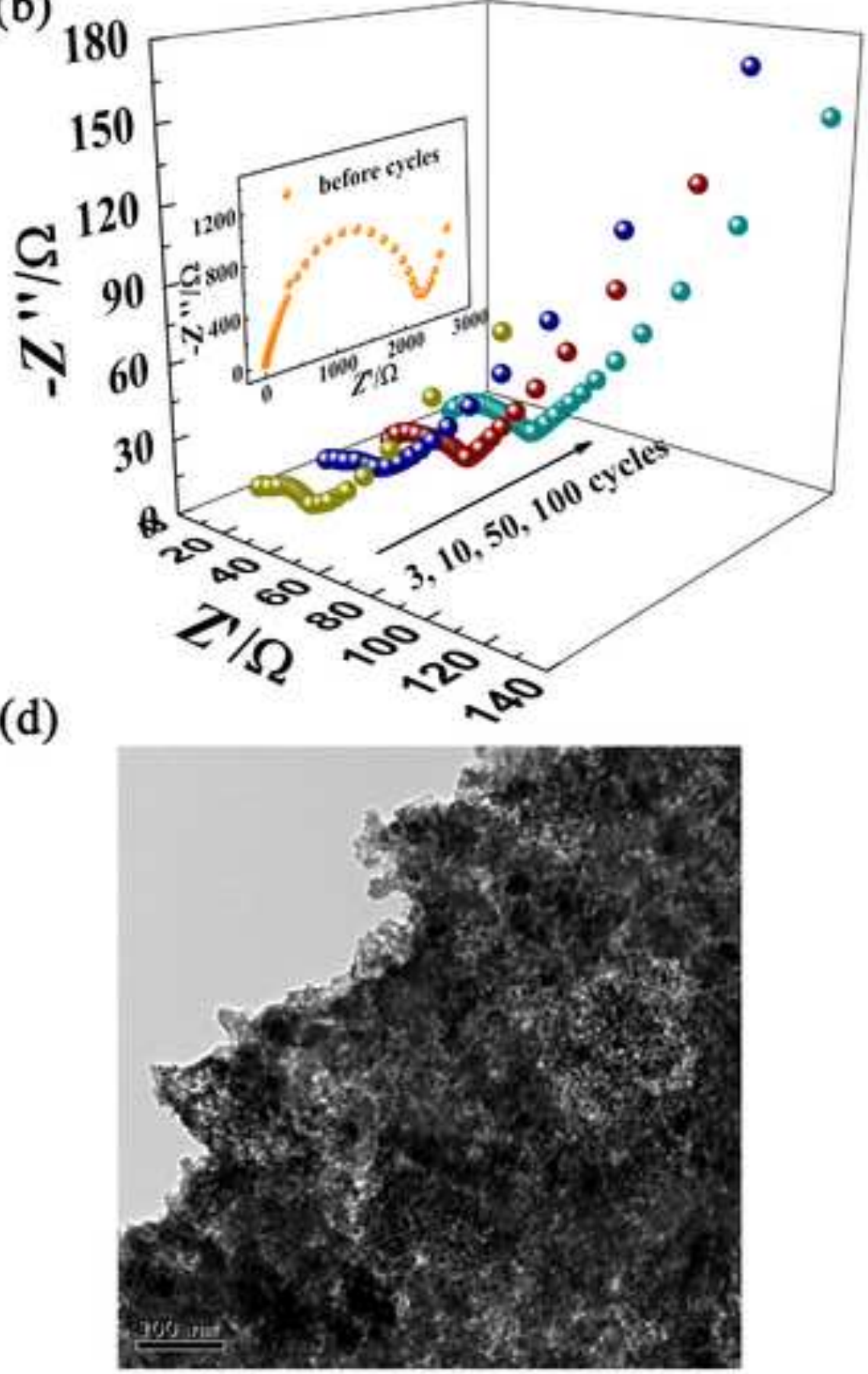